\title{
TCF12 controls oligodendroglial cell proliferation and regulates signaling pathways conserved in gliomas
}

Running title: TCF12 function in oligodendroglial cells and in gliomas

Sofia Archontidi ${ }^{1}$, Corentine Marie ${ }^{1}$, Beata Gyorgy ${ }^{1^{*}}$, Justine Guegan ${ }^{1^{*}}$, Marc Sanson ${ }^{1}$, Carlos Parras ${ }^{1}$ and Emmanuelle Huillard ${ }^{1 \#}$

${ }^{1}$ Sorbonne Université, Institut du Cerveau - Paris Brain Institute - ICM, Inserm, CNRS, APHP, Hôpital de la Pitié Salpêtrière, Paris, France

\section{* These authors contributed equally}

\#Author for correspondence; emmanuelle.huillard@icm-institute.org

The authors declare no conflicts of interest

\section{Acknowledgements:}

We acknowledge funding from Ligue Nationale contre le Cancer (to MS), Fondation ARC (PJA 20151203259 to EH), National Multiple Sclerosis Society (NMSS RG-150102851 to $\mathrm{CP}$ ), and the Fondation pour l'Aide à la Recherche sur la Sclérose en Plaques (ARSEP 2015, 2018, 2019 to CP), Fondation pour la Recherche Médicale (to CP). SA is recipient of scholarships from Ligue Nationale Contre le Cancer and Fondation pour la Recherche Médicale. We acknowledge the contribution of SiRIC CURAMUS (INCADGOS-Inserm_12560) which is financially supported by the French National Cancer Institute, the French Ministry of Solidarity and Health and Inserm. The research leading to these results has received funding from the program "Investissements d'avenir" ANR-10- IAIHU-06. Part of this work was carried out on the iGenSeq, CELIS, Histomics, PHENOPARC, Icm.Quant and Data and Analysis core facilities of ICM. We gratefully acknowledge Yannick Marie for assistance on RNA sequencing. We thank Isabelle Le Roux for critical input and reading of the manuscript. 


\section{Abstract}

Diffuse gliomas are primary brain tumors originating from the transformation of glial cells. In particular, oligodendrocyte precursor cells constitute the major tumoramplifying population in the gliomagenic process. We previously identified the TCF12 gene, encoding a transcription factor of the $E$ protein family, as being recurrently mutated in oligodendrogliomas. In this study, we sought to understand the function of TCF12 in oligodendroglial cells, the glioma lineage of origin. We first describe TCF12 mRNA and protein expression pattern in oligodendroglial development in the mouse brain. Second, by TCF12 genome wide chromatin profiling in oligodendroglial cells, we show that TCF12 binds active promoters of genes involved in proliferation, translation/ribosomes, and pathways involved in oligodendrocyte development and cancer. Finally, we perform OPC-specific Tcf12 inactivation in vivo and demonstrate by immunofluorescence and transcriptomic analyses that TCF12 is transiently required for OPC proliferation but dispensable for oligodendrocyte differentiation. We further show that $T c f 12$ inactivation results in deregulation of biological processes that are also altered in oligodendrogliomas. Together, our data suggest that TCF12 directly regulates transcriptional programs in oligodendroglia development that are relevant in a glioma context.

Keywords: TCF12/HEB, oligodendrocyte, glioma, proliferation, chromatin immunoprecipitation, transcriptomics, mouse model

\section{Main Text}

\section{Introduction}

Diffuse gliomas are the most prevalent malignant primary brain tumors in adults (Ostrom et al., 2017). Gliomas are classified according to their histological and genomic features, including the presence of mutations in isocitrate dehydrogenase genes (mostly in IDH1) and the status of the loss of the chromosomal arms $1 p$ and $19 q$ (termed as 1p/19q co-deletion) (Louis et al., 2016). The three main glioma entities are oligodendrogliomas (IDH mutated, $1 p / 19 q$ co-deleted), astrocytomas (IDH mutated, $1 p / 19 q$ intact) and glioblastomas (also termed GBM, IDH wild type, $1 p / 19 q$ intact), with the latter being most aggressive.

Gliomas contain cells with features of glial cells and neural stem/progenitor cells (NSC/NPCs) that are endowed with proliferative capacity (Bielle et al., 2017; Neftel et al., 2019; Tirosh et al., 2016). Furthermore, mounting evidence from genetically engineered mouse models indicate that cells with characteristics of NSC/NPCs, or oligodendrocyte precursor cells (OPCs) are potential cells of origin and responsible for tumor amplification in gliomas (Alcantara Llaguno et al., 2009; C. Liu et al., 2011; Persson et al., 2010; Weng et al., 2019). Thus, deciphering how alterations found in gliomas impact oligodendroglial lineage cells is critical to understand the cellular and molecular mechanisms underlying tumor development and progression. 
In the forebrain, OPCs are generated from NSC/NPCs at both embryonic and postnatal stages, and after proliferating and populating the brain, they start to differentiate into myelin-producing oligodendrocytes (OLs) around the second week after birth (Kessaris et al., 2006; Shen et al., 2021). Recent studies have described oligodendroglial differentiation as a continuum, starting from OPCs, followed sequentially by committed oligodendrocyte progenitors (COPs), newly formed OLs (NFOLs), myelin forming OLs (MFOLs) and finally by several populations of mature, axon ensheathing, OLs (MOLs) (Marques et al., 2016, 2018). OPCs constitute the major proliferating cell type the adult central nervous system (CNS), acting as source for differentiated OLs while maintaining the pool of cells available for differentiation (Dawson et al., 2003). OPC proliferation and differentiation properties are subjected to a strict, finely tuned regulation by a complex network of signaling, transcription and epigenetic factors (reviewed in (Parras et al., 2020; Sock \& Wegner, 2019).

Transcription factor 12 (TCF12, also called HTF4 or HEB) is a member the $\mathrm{E}$ protein family, a subclass of the basic helix-loop-helix (bHLH) protein family that includes TCF3 (E2A) and TCF4 (E2-2) (Massari \& Murre, 2000). Functionally, TCF12 has been reported to regulate the differentiation of lymphocytes (Emmanuel et al., 2018; Jones-Mason et al., 2012; Wojciechowski et al., 2007), the formation of germ layers from embryonic stem cells (Li et al., 2017; Yi et al., 2020; Yoon et al., 2015), osteoblast differentiation (Yi et al., 2017) and cranial suture development (Sharma et al., 2013). In the CNS, TCF12 is implicated in the development of midbrain dopaminergic neurons (Mesman \& Smidt, 2017) but its roles in the oligodendroglial lineage are not known. Early studies had demonstrated that TCF12 is expressed in oligodendrogliomas and astrocytomas (Riemenschneider et al., 2004). Furthermore, we and others previously reported that TCF12 is mutated in oligodendrogliomas (Labreche et al., 2015; Aihara et al., 2017; Suzuki et al., 2015). In particular we found that TCF12 mutations resulted in reduced transcriptional activity and were associated with aggressive tumor features (Labreche et al., 2015). However, how TCF12 mutations functionally impact the development of glioma cells of origin are not understood.

In this study, we explored the functions of TCF12 in oligodendroglia and gliomas, using chromatin binding profiling, transcriptomic and genomic analyses as well as genetic mouse models of Tcf12 conditional deletion. We report that TCF12 positively regulates OPC proliferation in vivo and further suggest putative implications that can be conserved in a glioma context.

\section{Methods}

Mice

Mice were housed, bred and treated in an authorized facility (agreement number A751319). All protocols and procedures involving mice were ethically reviewed and approved by the local ethics committee and the French Ministry of Research and Higher Education (approval number APAFIS\#20939-2020052811427837). Swiss 
124 (RjOrl:SWISS) mice were obtained from Janvier Laboratories (France). Tcf12flox mice

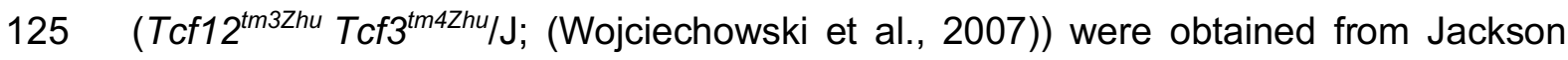
126 Laboratory and maintained as heterozygotes (Tcf12 flox/wt) by crossing them with 127 C57BL/6JRj mice (Janvier Laboratories). These mice were bred to PDGFR $:$ :CreER ${ }^{T}$ 128 (Kang et al., 2010) and Rosa26 LSL-YFP (Srinivas et al., 2001) to generate 129 PDGFRa::CreER ${ }^{T / w t} ;$ Rosa26 $6^{L S L-Y F P / L S L-Y F P} ; T c f 12^{\text {flox/wt }}$ males that were subsequently 130 bred with $T c f 12^{\text {flox/wt }}$ females. Both male and female animals were used for the 131 experiments. Genotyping was performed using standard protocols (sequences of 132 genotyping primers are available upon request). To induce Cre-mediated DNA 133 recombination, PDGFRa::CreER ${ }^{T}$;Rosa26 $6^{\text {LL-YFP }}$;cf12 flox mice were injected 134 subcutaneously with $100 \mu \mathrm{g} / \mathrm{g}$ of tamoxifen (T5648, Sigma; dissolved in corn oil; stock concentration of $20 \mathrm{mg} / \mathrm{mL}$ ) at $\mathrm{P} 13$, once a day for three consecutive days.

Immunofluorescence on frozen sections

Mice were sedated by xylazine (Rompun, $10-15 \mathrm{mg} / \mathrm{kg}$ ) and euthanized by intraperitoneal injection of sodium pentobarbital (Euthasol, $140 \mathrm{mg} / \mathrm{Kg}$ ). Mice were intracardially perfused with $\mathrm{NaCl} 0.9 \%$ followed by PFA $2 \%$ (Electron Microscopy Sciences 15713, diluted in PBS). Brains were post-fixed in PFA $2 \%$ and cryoprotected in $20 \%$ sucrose overnight at $4^{\circ} \mathrm{C}$. The following day, brains were embedded in OCT (16-004004, Tissue-Tek), frozen in dry-ice-chilled isopentane and stored at $-80{ }^{\circ} \mathrm{C}$. Fourteen-micron cryosections were obtained using a cryostat (Leica). Cryosections were air-dried at room temperature (RT) and then incubated with blocking solution, containing $10 \%$ normal goat serum (NGS) in $0.3 \%$ Triton X-100 (Sigma) in PBS (PBSTriton $0.3 \%$ ), for 1 hour at RT. Subsequently, sections were incubated with the primary antibodies either at $4^{\circ} \mathrm{C}$ overnight or at RT for 2 hours. After three washes with PBS, sections were incubated with fluorophore-labeled secondary antibodies for 1 hour at RT. Both primary and secondary antibodies were diluted in blocking solution (10\% NGS in $0.3 \%$ PBS-Triton). After three washes with PBS, sections were incubated in DAPI solution (300nM, Invitrogen D3571) for nuclear counterstaining, for 10 minutes at RT, and mounted using Fluoromount ${ }^{\mathrm{TM}}$ Aqueous Mounting Medium (Sigma-Aldrich). Slides were kept at $4^{\circ} \mathrm{C}$ until image acquisition. Immunofluorescent staining of fixed cells was performed as described above, except that a solution of $0.05 \%$ Tween 20 (P2287 Merck) in PBS was used instead of $0.3 \%$ Triton - PBS. The references of primary and secondary antibodies are given in Supplementary Information.

Image acquisition and quantification Images were captured using either a Leica Sp8x Confocal Microscope or a Zeiss widefield fluorescent microscope (equipped with an Apotome system). Image processing and analysis was performed on ZEN 2.0 blue edition software (Zeiss) or Fiji (Schindelin et al., 2012). Images were generated as maximum intensity projections (MIPs) of the entire imaging depth. Cell counting was done with Fijis Cell Counter plugin on MIPs. 
Mice (P12-P16) were euthanized with $\mathrm{CO}_{2}$ followed by immediate decapitation. Brains were rinsed in cold PBS and the dorsal region containing the cortex and corpus callosum was harvested. Dissociation was performed using the gentleMACS Octo Dissociator with Heaters (program 37C _NTDK _ 1, Miltenyi Biotec) with the appropriate tubes (gentleMACS C Tubes, 130-093-237, Miltenyi Biotec) and an enzymatic mix composed of $0.46 \mathrm{mg} / \mathrm{mL}$ papain (WOLS03126, Worthington), 0.1 $\mathrm{mg} / \mathrm{mL}$ DNAse (WOLS02139, Worthington) and $0.124 \mathrm{mg} / \mathrm{mL}$ L-cysteine (C7880, Sigma) and HBSS $1 \mathrm{X}$ supplied with $\mathrm{Ca}^{2+}$ and $\mathrm{Mg}^{2+}$. Upon dissociation, the suspension was filtered (130-110-916, Miltenyi Biotec), the cells were further resuspended in 5 volumes of cold HBSS and centrifuged at $300 \mathrm{~g}$ for 10 minutes at $4^{\circ} \mathrm{C}$. Additionally, a debris removal step was performed using a Debris Removal Solution (130-109-398, Miltenyi Biotec). Subsequently, cells were incubated with anti-O4 Microbeads (130094-543, Miltenyi Biotec) and magnetic separation was done using Multi-24 Column Blocks and the MultiMACS Cell24 Separator Plus (130-095-692 and130-098-637, Miltenyi Biotec). $\mathrm{O}^{+}$cells were collected in BSA $0.5 \%$ in PBS solution and counted. To characterize the sorted cell population, part of cell suspension was plated polyornithine coated (P4957, Sigma) and cultured for 2 hours before 4\% PFA fixation as described in (Marie et al., 2018).

\section{Chromatin immunoprecipitation followed by sequencing (ChIP-Seq)}

We used NPCs (cultures established from wild type Swiss neonatal mice) or acutely isolated $\mathrm{O}^{+}$MACSorted cells (harvested from P11-P12 wild type Swiss mice). We used $4.10^{6}$ cells for immunoprecipitation with TCF12 antibody and $10^{6}$ cells for immunoprecipitation with each histone (H3K27Ac, H3K4me3, H3K27me3) antibody. Cells were fixed in PFA $1 \%$ for 10 minutes at RT. Fixation was quenched with $125 \mathrm{mM}$ glycine (G8898, Sigma) for 5 minutes and cells were washed in cold PBS supplied with protease inhibitor cocktail (11873580001, Roche). Cells were stored as dry cell pellet at $-80^{\circ} \mathrm{C}$ until further processed. The next steps were performed using iDeal ChIP-Seq kit for Transcription Factors (C01010055, Diagenode). Briefly, cells were lysed, and chromatin was sheared using a Bioruptor Pico sonicator (10 sonication cycles 30" ON/ 30" OFF, Diagenode). Sheared chromatin was incubated under constant rotation at $4^{\circ} \mathrm{C} \mathrm{O} / \mathrm{N}$ with Protein A-coated magnetic beads, coupled with rabbit anti-TCF12 antibody (5 $\mu \mathrm{g}$, SAB3500566, Sigma). Elution, cross-link reversal and DNA purification steps were performed according to the manufacturer's protocol (Diagenode). Input (non-immunoprecipitated sheared chromatin) was used as control. Protocols for H3K27Ac, H3K4me3, H3K27me3, are described elsewhere (C Marie and C Parras, unpublished data). The ChIP-Seq libraries were prepared using TruSeq ChIP library preparation kit (ILLUMINA) and sequenced with a Nextseq 500 platform (ILLUMINA, $5710^{6}$ of 75 bp pair-end reads per sample). Sequenced datasets were processed with the Galaxy suite (https://usegalaxy.org/). Reads were trimmed using Cutadapt and Trimmomatic. Data was aligned to the mouse mm10 genome, using Bowtie2. PCRderived duplicates were removed using PICARD MarkDuplicates and blacklisted regions were removed with blacklist. Bigwig coverage files were generated with bamCoverage and peak calling was performed using MACS (Model-based Analysis of 
211 ChIP-Seq) with options: --keep-dup 1, --narrow, --nomodel and filtered according to 212 the following criteria: (i) length $>=100 \mathrm{bp}$ and (ii) $\mathrm{p}$-value $<=5 \%$. The Input for each 213 individual experiment was used as control. Representation of the data was done using 214 IGV browser (https://software.broadinstitute.org/software/igv/ , (Robinson et al., 215 2011)). Overlapping, region annotation and correlations were done using Genomatix 216 (www.genomatix.de). Gene set enrichment analyses were done using Enrichr 217 (https://maayanlab.cloud/Enrichr/,(Chen et al., 2013)). "Promoters" correspond to 218 regions $1000 \mathrm{bp}$ upstream of transcription start site (TSS) and 10bp downstream of 219 TSS (Genomatix). "Enhancers" correspond to the regions associated with the 220 presence of histone marks outside promoters.

\section{RNA extraction, RT-qPCR and sequencing}

$222 \mathrm{mRNAs}$ of $\mathrm{O}^{+}$MACSorted cells were extracted using the Macherey-Nagel NucleoSpin 223 RNA XS kit (740902.50, Macherey-Nagel) and quantified with Nanodrop 224 spectrophotometer. RNAs were reverse transcribed to CDNA using the Maxima 1str 225 cDNA Synth Kit (K1642, LifeTechnologies). Quantitative PCR was performed using 226 LightCycler 480 SYBR Green I Master Mix (4707516001, Roche) on a LightCycler® 22796 thermocycler. Samples were run in replicates (duplicates or triplicates). Primers 228 details are listed in the Supplementary Information. Gapdh and Tbp genes were used 229 for normalization. Analyses were performed using the delta-delta Cq method.

230 For RNA sequencing, RNA-Seq libraries were prepared using the NEBNext Ultra II 231 Directional RNA Library Prep Kit (NEB) and sequenced with the Novaseq 6000 232 platform (ILLUMINA, 32*106 $100 \mathrm{bp}$ pair-end reads per sample). Quality of raw data 233 was evaluated with FastQC. Poor quality sequences were trimmed or removed with 234 fastp tool, with default parameters, to retain only good quality paired reads. Illumina 235 DRAGEN bio-IT Plateform (v3.6.3) was used for mapping on mm10 reference genome 236 and quantification with gencode vM25 annotation gtf file. Library orientation, library 237 composition and coverage along transcripts were checked with Picard tools. 238 Subsequent analyses were conducted with $\mathrm{R}$ software. Data were normalized with 239 edgeR (v3.28.0) bioconductor packages, prior to differential analysis with $\mathrm{glm}$ 240 framework likelihood ratio test from edgeR package workflow. Multiple hypothesis 241 adjusted $p$-values were calculated with the Benjamini-Hochberg procedure to control 242 False Discovery Rate (FDR). Finally, enrichment analysis was conducted with 243 clusterProfiler R package (v3.14.3) using Gene Set Enrichment Analysis (GSEA), on 244 hand curated collections and on collections of the MSigDB. For the differential 245 expression analyses, low expressed genes were filtered, sex was used as covariable 246 and the cut-offs applied were: FDR $<0.05$ and $\log 2 \mathrm{FC}>0.5$.

\section{Statistical analysis}

248 Data were plotted and analyzed using MS Excel, GraphPad Prism 8 or R Studio, 249 unless otherwise specified. In bar graphs, data are presented as mean + standard 250 error of the mean (SEM). Points indicate independent biological samples (n) of the 251 same genotype. Statistical tests used are specified in the figure legends. 
253

254

255

256

257

258

259

260

261

262

263

264

265

266

267

268

269

270

271

272

273

274

275

276

277

278

279

280

281

282

283

284

285

286

287

288

289

290

291

292

293

294

295

296

\section{Results}

\section{TCF12 is altered in gliomas}

To extend previous studies and obtain a broad view of the type and distribution of TCF12 alterations in gliomas, we queried the "Lower Grade Glioma" (LGG, grades IIIII) and "Glioblastoma Multiforme" (GBM, grade IV) data sets of the TCGA PanCancer Atlas (containing data for 514 and 592 tumors respectively). By interrogating those datasets for mutations and copy number alterations, we found that TCF12 alterations are present in all glioma types (Supplementary Figure 1A). TCF12 is altered in approximately $27 \%$ and $18 \%$ of the GBM and LGG respectively (Figure $1 \mathrm{~A}$ ). In both tumor types, $70-80 \%$ of TCF12 alterations correspond to heterozygous losses (Figure 1B). We next compared the occurrence of TCF12 alterations with other common glioma alterations. We found that TCF12 alterations co-occur with the most common glioma alterations (TP53, PTEN, NF1, EGFR, CDKN2A) but do not co-occur significantly with $I D H 1$ or $C I C$ alterations (Supplementary Figure $1 \mathrm{~A}$ and $1 \mathrm{~B}$; Supplementary Table 1), further indicating that TCF12 alterations are not specific to a glioma type. We next analyzed whether TCF12 alterations were associated with patient clinical outcome. We did not detect an association between TCF12 alterations and patient overall survival (Figure 1C and 1D). However, when considering TCF12 high and low expression levels (Supplementary Table 2), we noted that patients with higher TCF12 expression had a better survival compared to TCF12-low patients, both in GBM and LGG (Figure 1E and 1F), in line with a recently published study (Noorani et al., 2020). Together, these data suggest a broad and tumor suppressive function for TCF12 in gliomas.

\section{TCF12 is expressed in oligodendroglial cells}

Given that cells with features of OPCs constitute a major tumor driving population in gliomas (C. Liu et al., 2011; Weng et al., 2019), we thus explored TCF12 function in these cells. In order to characterize Tcf12 expression across the oligodendrocyte lineage, we first interrogated a bulk RNA-Seq transcriptome database of mouse and human cerebral cortex cell types (Zhang et al 2014), finding that Tcf12 is expressed in neurons, astrocytes and in oligodendroglial cells in the mouse and human brain, with higher expression levels in oligodendroglia (Figure 2A). We next processed and integrated single cell transcriptomic datasets of embryonic and postnatal mouse oligodendroglial lineage cells (Marques et al., 2016; 2018) to further explore Tcf12 expression across the oligodendrocyte $(\mathrm{OL})$ lineage (Supplementary Figure $2 \mathrm{~A}$ and 2B). Analysis of this data revealed Tcf12 expression in NSCs, NPCs, and OL lineage cells, with Tcf12 expression being higher in early progenitor cells and differentiating OLs, compared to mature OLs (Figure 2B,C). Given the functional compensation among E-proteins suggested in neuroglial and other lineages (Ravanpay \& Olson, 2008; Wedel et al., 2020; Zhuang et al., 1998), we also analyzed the expression of Tcf3 and Tcf4 in OL lineage cells. WhileTcf3 was expressed in few cells and at quite low levels, Tcf4 was expressed in a higher percentage of NSCs, NPCs, and oligodendroglia than Tcf12, with a peak of expression in NPCs and OPCs 
297 (Supplementary 2C). Finally, we validated the presence of TCF12 protein in 298 oligodendroglial cells in wild type mice by performing immunofluorescence of TCF12 299 along with PDGFRa (identifying OPCs), and the combination of CC1 and OLIG1 300 (identifying OLs, Figure 2D). We show that TCF12 protein is present in OPCs and 301 differentiating OLs in the mouse corpus callosum, at postnatal and adult stages (Figure 302 2E-F).

303

\section{TCF12 primarily occupies active promoter regions in oligodendroglial cells}

To explore the potential roles mediated by TCF12 in the oligodendrocyte lineage, we next sought to identify putative TCF12 gene targets and pathways in oligodendroglial cells, by generating the chromatin binding profiles of TCF12 in NSC/NPCs and oligodendroglia. To do so, we first performed magnetic-activated cell sorting (MACS) using $\mathrm{O} 4$ antibodies (recognizing OPCs/OLs, (Dincman et al., 2012) to purify oligodendroglial cells from wild type postnatal day 12 (P12) mice, obtaining a population composed of $\sim 30 \%$ OPCs and $\sim 60 \%$ OLs (thereafter termed "OPCs/OLs", Supplementary Figure $3 A-B)$. To assess cell type-specific and overlapping targets for TCF12, we also prepared neurosphere cultures of neural progenitor cells (thereafter termed "NPCs", Supplementary Figure 3A). We then performed chromatin immunoprecipitation followed by DNA sequencing (ChIP-Seq) using antibodies directed against TCF12 and histone marks defining status of regulatory elements as active, poised and repressed. Elements harboring H3K27Ac/H3K4me3 were considered as active, $\mathrm{H} 3 \mathrm{~K} 4 \mathrm{me} 3$ alone as poised, and $\mathrm{H} 3 \mathrm{~K} 27 \mathrm{me} 3$ as repressed (Rada-Iglesias et al., 2011). Peak calling identified 18405 TCF12 binding sites in NPCs and 28654 in OPCs/OLs that were associated with 6947 and 15670 genes, respectively (Figure 3A, Supplementary Table 3). Only 3032 genes were shared between OPCs/OLs and NPCs, suggesting that TCF12 binding is cell type specific (Figure 3A). Analysis of the distribution of TCF12 binding sites over genomic regions (promoters, exons, introns, and intragenic regions) indicated that TCF12 binding in OPCs/OLs was particularly enriched in promoters, representing $42 \%$ of bound regions, compared to only $7 \%$ in NPCs (Figure $3 \mathrm{~B}$ ). Visualizing the genomic distribution of TCF12 binding sites further revealed a strong enrichment of TCF12 binding in the proximity of promoters in OPCs/OLs but not in NPCs, whereas TCF12 bound the vicinity of enhancers, defined as regions harboring a histone mark located away from a transcription start site, in both NPCs and OPCs/OLs (Figure 3C). We then characterized whether the regulatory regions bound by TCF12 were active, poised or repressed and found that promoter regions bound by TCF12 were mainly active both in OPCs/OLs and NPCs (52\% active, $12 \%$ poised, and $6 \%$ repressed in OPCs/OLs, and $63 \%$ active, $23 \%$ poised, and $5 \%$ repressed in NPCs), while enhancer regions bound by TCF12 binding corresponded mostly to poised enhancers $(52 \%$ in OPCs/OLs and $69 \%$ in NPCs) (Figure 3D and Supplementary Figure 3C, Supplementary Table 3). Altogether, our findings of TCF12 occupancy in gene regulatory regions enriched in active or poised chromatin marks in both OPCs/OLs and NPCs, suggest that it directly activates gene expression in both cell types. Notably, the promoters of genes known as markers of OPCs (Pdgfra) and OLs (Itpr2, Mbp), as well 
as proliferation markers (Mki67, Cdkn1a), were bound by TCF12 in OPCs/OLs and displayed active histone marks (Figure 3E). Finally, we performed enrichment analysis of the genes associated with TCF12 binding at active promoters in OPCs/OLs. This analysis revealed enrichment of pathways related to proliferation, translation/ribosomes, proteasome, and signaling pathways involved in oligodendrocyte development and cancer (such as MYC, TGFß, PI3K/AKT/mTOR, WNT-beta catenin, p53, Notch) (Figure 3F; Supplementary Figure 3D; Supplementary Table 4). Therefore, all together, these data suggest that TCF12 regulates oligodendrocyte development, by positively regulating gene expression.

\section{TCF12 inactivation in OPCs in vivo leads to proliferation defects}

To further characterize the roles of TCF12 in oligodendrocyte lineage, we generated an inducible Tcf12 knockout mouse model. To do so, we combined a $T c f 12^{f l o x}$ mice having loxP sites flanking the exons encoding the bHLH domain (Mesman \& Smidt, 2017; Wojciechowski et al., 2007), with mice carrying Pdgfra::CreER $R^{T}$ driver (Kang et al., 2010) and YFP inducible reporter (Srinivas et al., 2001). Thus, in this Pdgfra::CreER ${ }^{T}$;Rosa26 ${ }^{\text {LSL-YFP }}$; Tcf12 $2^{\text {flox }}$ model, TCF12 inactivation can be induced specifically in OPCs upon tamoxifen-dependent Cre-mediated recombination and the cell fates of Tcf12-mutant cells can be traced by the YFP reporter. In this model, we compared mutant heterozygous $\left(T c f 12^{\text {het }}\right)$ and homozygous $\left(T c f 12^{\text {hom }}\right)$ animals with intact Tcf12 (Tcf12 ${ }^{\text {ctrl }}$ ) littermates (Supplementary Figure 4A-B). As a first step, we administrated tamoxifen at $\mathrm{P} 13$, at the peak of oligodendrocyte differentiation in the corpus callosum, and performed our analysis at P16 to focus on the immediate effects following Tcf12 inactivation (Figure 4A). We first validated the efficacy of Cre-mediated recombination of the $T c f 12^{f l o x}$ allele by quantifying mutated $T c f 12$ transcripts by RTqPCR on OPCs/OLs purified by $\mathrm{O}^{+}$magnetic sorting from P16 cortices. We observed a $25 \%$ to $50 \%$ decrease in Tcf12 transcript levels in $T c f 12^{\text {het }}$ and $T c f 12^{\text {hom }}$ animals respectively, compared to $T c f 12^{\text {ctrl }}$ (Supplementary Figure 4D), which is consistent with $\sim 60 \%$ of $\mathrm{O} 4+$ cells being recombined $\left(\mathrm{YFP}^{+}\right.$) at the time of analysis (Supplementary Figure 4E). We next asked whether Tcf12 inactivation affected OPC proliferation and differentiation properties by performing combined immunostaining with antibodies against GFP to detect the recombined $\left(\mathrm{YFP}^{+}\right)$cells, PDGFR $\alpha / \mathrm{Ki} 67$ to label OPCs and their proliferative status, and CC1/OLIG1 to label different OL stages (Figure 4B, C). Remarkably, while the density of recombined OPCs (PDGFR $\alpha^{+} \mathrm{GFP}^{+} / \mathrm{mm}^{2}$ ) (Figure 4D) and the fraction of recombined OPCs (PDGFR $\alpha^{+} \mathrm{GFP}^{+} / \mathrm{PDGFR} \alpha^{+}$and PDGFR $\alpha^{+} \mathrm{GFP}^{+} /$ $\mathrm{GFP}^{+}$) (Figure 4E,F) remained unchanged in the corpus callosum across the different genotypes, the fraction of proliferating OPCs was reduced by two-fold in Tcf $12^{\text {hom }}$ animals $\left(28.2 \% \pm 3.94 \%\right.$ in $T c f 12^{\text {ctrl }}, 25.3 \% \pm 3.31 \%$ in $T c f 12^{\text {het }}$, and $13.6 \% \pm 2.42 \%$ in Tcf12 $2^{\text {hom }}$, Figure 4G). This result parallels our ChIP-Seq analysis, which indicated a positive regulation of proliferation by TCF12. We then analyzed different stages of differentiating OLs identified by their differential expression of CC1 and OLIG1 (Marie et al., 2018; Nakatani et al., 2013). We did not detect any difference among genotypes 
trend towards more mature oligodendrocytes in $T c f 12^{\text {hom }}$ mice (Figure $4 \mathrm{H}-\mathrm{I}$ ). Together, our data suggest that TCF12 is a positive regulator of OPC proliferation and likely dispensable in OL differentiation.

To address whether changes in OPC proliferation and differentiation persist following Tcf12 inactivation, we induced Pdgfra::CreERT;RosaLSL-YFP;Tcf12 flox mice as previously at $\mathrm{P} 13$ and harvested them ten days later (P23; Supplementary Figure 4F$\mathrm{N}$ ). We noticed that the densities of recombined cells (PDGFRa+GFP+/mm2) were similar among genotypes (Supplementary Figure 4I). In addition, OPC proliferation did not change between genotypes, nor differentiating oligodendrocytes (Supplementary Figure $4 \mathrm{~J}-\mathrm{N}$ ). These results suggest that TCF12 is, in the long term, dispensable for proper OPC proliferation and differentiation.

\section{Transcriptomic analyses of Tcf12-deficient oligodendroglial cells highlight} differentiation defects and deregulation of cancer related pathways

To gain insights into the molecular mechanisms altered upon Tcf12 inactivation, we performed a transcriptomic analysis. We purified OPCs/OLs $\left(\mathrm{O}^{+}\right.$cells $)$at $\mathrm{P} 16$ from control and mutant mice three days after tamoxifen induction and performed RNA sequencing (Figure 5A). Using stringent criteria of statistical analysis (FDR $<0.05$, $\log 2 \mathrm{FC}>0.5$ ), we detected few differentially expressed genes (Supplementary Table $5)$. We thus analyzed the data by the method of gene set enrichment analysis (GSEA). To this goal, we first performed GSEA using a hand-curated collection of oligodendroglial gene sets derived from publications (Marques et al., 2016, 2018; Weng et al., 2019; Zhang et al., 2014) (collection provided in Supplementary Table 6). In line with our observations from immunofluorescence analysis, we observed a downregulation of gene sets related to OPCs and their proliferation in mutant animals compared to controls (Figure 5B and Supplementary Table 7). Moreover, we noted a positive enrichment of gene sets related to more differentiated oligodendrocytes in mutant compared to control animals (Figure 5B and Supplementary Table 7). Interestingly, enrichment analysis comparing $T c f 12^{\text {Het }}$ vs $T c f 12^{c t r l}$ cells revealed similar defects in proliferation and differentiation, although we were not able to detect these changes with the immunofluorescence approach (Supplementary Figure 5A).

To establish a broader view of the data beyond the oligodendrocyte signatures, we carried out GSEA using the highly curated HALLMARK collection from the molecular signature database (MSigDB) (Liberzon et al., 2015). In agreement with the previous analysis, comparison between $T c f 12^{\text {hom }}$ and controls also revealed a negative enrichment of cell cycle processes (E2F targets, mitotic spindle, G2M checkpoint), together with epithelial-mesenchymal transition (EMT) gene sets, and a positive enrichment of pathways related to metabolism (oxidative phosphorylation, fatty acid, adipogenesis, and reactive oxygen species) and MYC target genes (Figure 5C). Parallel analysis of $T c f 12^{\text {het }}$ compared to controls showed no enrichment in cell cycle processes, but upregulation of processes related to cholesterol homeostasis, and downregulation of immune signatures (inflammatory and interferon responses), EMT and NOTCH signaling (Supplementary Figure 5B). Querying additional collections from the molecular signature database (REACTOME, KEGG, 
GO_Biological_Process), we observed that Tcf12 inactivation was also associated with negative regulation of developmental pathways (such as $\mathrm{NOTCH}, \mathrm{BMP}$ ) and pathways related to cancer (such as cell cycle, extracellular matrix, ribosome, TP53,) (Supplementary Figure 5C). Interestingly, the absence of functional TCF12 induced a deregulation of ribosome biogenesis and translation-related pathways (Figure 5D, Supplementary Figure $5 \mathrm{C}$ ) which are a strictly tuned in a multi-staged process controlling diverse cellular responses, such as cell proliferation and growth (Hetman \& Slomnicki, 2019).

\section{Conservation of TCF12 regulated pathways in human gliomas}

To determine how TCF12-dependent pathways may be relevant in gliomas, we took advantage of our previously published cohort of TCF12-mutated oligodendrogliomas (Labreche et al., 2015). We re-analyzed the transcriptomics data, comparing samples with TCF12 alterations (mutations and/or loss of heterozygosity and/or copy number loss of heterozygosity without loss of heterozygosity; $n=20$ ) to non-altered (nonmutated and normal TCF12 genomic status; $n=35$ ) samples (Supplementary Table 8). We performed gene set enrichment analysis using the HALLMARK collection from the molecular signature database. Interestingly, this analysis showed positive enrichment of pathways related to MYC, oxidative phosphorylation, cell cycle (E2F targets) in TCF12-altered tumors, similar to our analysis of Tcf12-inactivated cells (Figure 5E). In addition, EMT and immune response signatures were negatively enriched in TCF12altered tumors. We also interrogated the REACTOME collection and found that pathways related to translation and regulation of p53 activity were positively enriched in TCF12-altered tumors (Figure 5F). These data indicate that the TCF12-regulated processes that we identified from our molecular analyses of mouse oligodendroglial cells are conserved in a glioma setting.

\section{Discussion}

Oligodendrocyte precursor cells (OPCs) have been proposed to be the cells of origin for gliomas and responsible for tumor expansion (C. Liu et al., 2011; Persson et al., 2010; Sugiarto et al., 2011; Weng et al., 2019), although mutations may arise as early as the neural stem cell stage (J. H. Lee et al., 2018; C. Liu et al., 2011). Understanding how genes altered in gliomas impact the lineage of origin can provide insights into their implication in gliomas, as these functions may be conserved in a tumor context. In this study, we aimed to explore the roles of TCF12 in the oligodendroglial lineage and in gliomagenesis. Although TCF12, similar to other members of the E protein family (TCF3, TCF4), is a ubiquitously expressed protein, its function remains poorly characterized in cell-specific contexts. Tcf12 was reported to be expressed in spinal cord oligodendroglial cells and oligodendroglial cultures (Fu et al., 2009; Sussman et al., 2002; Wedel et al., 2020). Here, querying resources of bulk and single cell transcriptomic data sets from embryonic and postnatal mouse brain (Marques et al., 2016, 2018; Zhang et al., 2014), we find that Tcf12 is expressed throughout oligodendrocyte lineage development, with higher transcript levels in progenitor and 
471 cells at early stages of differentiation. By immunofluorescence, we demonstrate a

472 similar pattern of TCF12 protein in postnatal and adult oligodendroglia, with TCF12 levels peaking in OPC and differentiating oligodendrocytes.

We report the first analysis of TCF12 genome wide binding sites in oligodendroglial cells acutely isolated from the postnatal cerebral cortex. TCF12 binding sites were enriched in promoter regions compared to other genomic regions, and associated with active histone marks, suggesting that TCF12 acts as a transcriptional activator in oligodendrocyte lineage cells. The key regulators of oligodendrocyte development ASCL1 and OLIG2 are known to dimerize with Eproteins to control gene expression. TCF12 binding sites partially overlap with those of ASCL1 and OLIG2 (C Marie and C Parras, unpublished data) suggesting interaction between TCF12 and these proteins in transcriptional regulation of oligodendroglial cells. Interestingly, a recent study pointed to a preferential interaction of TCF12 with OLIG1 in HEK cells (Wedel et al., 2020). Future studies will be needed to determine the contribution of the different TCF12 heterodimers in the regulation of OPC proliferation and differentiation.

We further show that specific inactivation of Tcf12 in postnatal OPCs result in a significant decrease in the proportion of proliferating OPCs without impacting the proportions of OPCs and oligodendrocytes. This result indicates that TCF12 controls OPC proliferation, as suggested by our ChIP-Seq data and in agreement with our observations of high Tcf12 expression in neural stem and progenitors of the mouse brain. Transcriptomic analyses of Tcf12 deficient cells offered a higher resolution of altered processes and further pointed out differentiation defects, that we were unable to detect from our immunohistochemical analysis, although we noted a trend towards more mature oligodendrocytes in Tcf12-deficient mice. Enrichment of oligodendrocyte signatures in Tcf12-deficient cells may reflect the consequences of decreased OPC proliferation. Our data thus suggest that in the oligodendroglial lineage, TCF12 may primarily act on proliferation, rather than differentiation. This is in agreement with a recent study showing that ectopic TCF12 does not affect oligodendrocyte differentiation of brain organotypic slices (Wedel et al., 2020). However, our finding of TCF12 binding to the promoters of oligodendrocyte genes implies a possible and subtle implication of TCF12 in the control of differentiation. We noted that the effects of Tcf12 inactivation on proliferation are transient. Given that all three E-protein genes (Tcf12, Tcf3, Tcf4) are expressed in developing oligodendrocytes, it is possible that TCF3 and TCF4 may compensate for TCF12 deficiency, as shown for Tcf12-/- mouse cerebella that display upregulation of Tcf4 transcripts (Ravanpay \& Olson, 2008). Although we did not detect an upregulation in Tcf3 and Tcf4 transcripts in Tcf12508 deficient OPCs three days post inactivation (Supplementary Table 5), we cannot 509 exclude that a compensation takes place later on, given the strong levels of Tcf4 510 transcripts present in OPCs.

511 Transcriptomic analysis of both Tcf12-deficient oligodendroglia (this study) and 512 TCF12-mutated gliomas (Labreche et al., 2015) revealed few significantly differentially 513 expressed genes in the context of TCF12 inactivation compared to wild type TCF12. 514 This result is intriguing given that we find TCF12 binds over 15,000 genes in the 
515 genome of oligodendroglial cells and therefore one might expect substantial 516 deregulation of gene expression in the absence of functional TCF12. However, the 517 apparent lack of gene expression differences may in fact highlight the diversity of 518 processes directly controlled by TCF12, as many of them may interact and regulate 519 each other, leading to an overall normalization of gene expression. 520 Interestingly, our ChIP-Seq and RNA-Seq data suggest a control by TCF12 of several processes involved in cancer, many of which are also perturbed in TCF12 altered oligodendrogliomas. For example, we observed a negative enrichment of terms related to the extracellular matrix and epithelial-mesenchymal transition (EMT) in Tcf12-deficient OPCs and in TCF12-altered oligodendrogliomas. Accordingly, TCF12 was shown to repress E-cadherin expression, and its expression has been correlated with increased invasion, migration, and metastasis in several cancers (He et al., 2016; C.-C. Lee et al., 2011; Luo et al., 2020), including GBM (Zhu et al., 2021). An important difference we noted between our mouse model and TCF12-altered oligodendrogliomas is that while proliferation is decreased in Tcf12-deficient OPCs, loss of TCF12 is associated with increased proliferation in human oligodendrogliomas. We previously showed that TCF12 mutations in oligodendrogliomas were associated with more aggressive tumor features (Labreche et al., 2015), indicative of a tumorsuppressive function for TCF12. In line with these findings, TCF12 was recently identified as a master regulator of the differentiated, rather than stem-like, state in glioblastomas (Castellan et al., 2021). In contrast, a previous study showed that TCF12 silencing decreased proliferation and invasion in glioma cell lines (Godoy et al., 2016). All these data suggest that mechanisms induced by the mutational and cellular contexts in gliomas may interfere with TCF12-mediated regulation of proliferation.

Importantly, our study implies novel roles for TCF12 in the control of ribosome biogenesis and translation. TCF12 has been shown to bind the bHLH transcription factor MYC in rat fibroblasts (Agrawal et al., 2010). MYC directly controls ribosome biogenesis and translation, by inducing the transcription of ribosomal RNA, ribosomal proteins and genes involved in the maturation of ribosomal RNAs (Piazzi et al., 2019). Perturbation of the ribosome biogenesis process has been shown to activate p53 (Piazzi et al., 2019). Interestingly, processes related to MYC, TP53 and ribosome/translation were enriched in both Tcf12-deficient oligodendroglial cells and TCF12-altered oligodendrogliomas. In addition, we detected binding of TCF12 on promoters of $M y c, M y c n$ and genes involved in ribosome biogenesis (such as Rp/5,

$549 R u v b / 2, F b /)$ in oligodendroglial cells. Our study is the first to suggest a link between 550 TCF12 and ribosome biogenesis. Of note, interactions between E-proteins and 551 ribosome biogenesis were previously reported: TCF4 is detected in the nucleolus, 552 where ribosome biogenesis occurs, and loss of function mutants inhibit protein 553 synthesis in rat hippocampal neurons (Slomnicki et al., 2016). Moreover, TCF4 554 overexpression represses MYC target genes in a leukemic cell line (N. Liu et al., 2019). 555 In conclusion, our study suggests that TCF12 directly regulates many signaling 556 pathways in oligodendroglia development that are relevant in a glioma context. 


\section{Author contributions}

559 SA and EH conceptualized the study. SA, CM, CP and EH designed experiments and analyzed data. SA and CM performed experiments. BG, JG and CP analyzed transcriptomic data generated in this paper and from public databases. MS, CP and EH obtained funding. EH supervised the study. SA, CP and EH wrote the manuscript. All authors revised the manuscript.

\section{References}

566

Agrawal, P., Yu, K., Salomon, A. R., \& Sedivy, J. M. (2010). Proteomic profiling of Mycassociated proteins . Cell Cycle, 9(24). https://doi.org/10.4161/cc.9.24.14199

Aihara, K., Mukasa, A., Nagae, G., Nomura, M., Yamamoto, S., Ueda, H., Tatsuno, K., Shibahara, J., Takahashi, M., Momose, T., Tanaka, S., Takayanagi, S., Yanagisawa, S., Nejo, T., Takahashi, S., Omata, M., Otani, R., Saito, K., Narita, Y., ... Saito, N. (2017). Genetic and epigenetic stability of oligodendrogliomas at recurrence. Acta Neuropathologica Communications, 5(1). https://doi.org/10.1186/s40478-017-0422-z

Alcantara Llaguno, S., Chen, J., Kwon, C.-H., Jackson, E. L., Li, Y., Burns, D. K., AlvarezBuylla, A., \& Parada, L. F. (2009). Malignant Astrocytomas Originate from Neural Stem/Progenitor Cells in a Somatic Tumor Suppressor Mouse Model. Cancer Cell, 15(1), 45-56. https://doi.org/10.1016/j.ccr.2008.12.006

Bielle, F., Ducray, F., Mokhtari, K., Dehais, C., Adle-Biassette, H., Carpentier, C., Chanut, A., Polivka, M., Poggioli, S., Rosenberg, S., Giry, M., Marie, Y., Duyckaerts, C., Sanson, M., Figarella-Branger, D., \& Idbaih, A. (2017). Tumor cells with neuronal intermediate progenitor features define a subgroup of $1 \mathrm{p} / 19 \mathrm{q}$ co-deleted anaplastic gliomas. Brain Pathology, 27(5), 567-579. https://doi.org/10.1111/bpa.12434

Castellan, M., Guarnieri, A., Fujimura, A., Zanconato, F., Battilana, G., Panciera, T., Sladitschek, H. L., Contessotto, P., Citron, A., Grilli, A., Romano, O., Bicciato, S., Fassan, M., Porcù, E., Rosato, A., Cordenonsi, M., \& Piccolo, S. (2021). Single-cell analyses reveal YAP/TAZ as regulators of stemness and cell plasticity in glioblastoma. Nature Cancer, 2(2), 174-188. https://doi.org/10.1038/s43018-020-00150-z

Chen, E. Y., Tan, C. M., Kou, Y., Duan, Q., Wang, Z., Meirelles, G., Clark, N. R., \& Ma'ayan, A. (2013). Enrichr: interactive and collaborative HTML5 gene list enrichment analysis tool. BMC Bioinformatics, 14(1). https://doi.org/10.1186/1471-2105-14-128

Dawson, M. R. L., Polito, A., Levine, J. M., \& Reynolds, R. (2003). NG2-expressing glial progenitor cells: An abundant and widespread population of cycling cells in the adult rat CNS. Molecular and Cellular Neuroscience, 24(2), 476-488. https://doi.org/10.1016/S1044-7431(03)00210-0

Dincman, T. A., Beare, J. E., Ohri, S. S., \& Whittemore, S. R. (2012). Isolation of cortical mouse oligodendrocyte precursor cells. Journal of Neuroscience Methods, 209(1). https://doi.org/10.1016/j.jneumeth.2012.06.017

Emmanuel, A. O., Arnovitz, S., Haghi, L., Mathur, P. S., Mondal, S., Quandt, J., Okoreeh, M. K., Maienschein-Cline, M., Khazaie, K., Dose, M., \& Gounari, F. (2018). TCF-1 and HEB cooperate to establish the epigenetic and transcription profiles of CD4 + CD8 + thymocytes. Nature Immunology, 19(12), 1366-1378. https://doi.org/10.1038/s41590018-0254-4

Fu, H., Cai, J., Clevers, H., Fast, E., Gray, S., Greenberg, R., Jain, M. K., Ma, Q., Quu, M., Rowitch, D. H., Taylor, C. M., \& Stiles, C. D. (2009). A Genome-Wide Screen for Spatially Restricted Expression Patterns Identifies Transcription Factors That Regulate Glial Development. Journal of Neuroscience. https://doi.org/10.1523/JNEUROSCI.016009.2009

Godoy, P. R. D. v, Montaldi, A. P. L., \& Sakamoto-Hojo, E. T. (2016). HEB silencing induces anti-proliferative effects on U87MG cells cultured as neurospheres and monolayers. Molecular Medicine Reports, 14(6), 5253-5260. https://doi.org/10.3892/mmr.2016.5877 
He, J., Shen, S., Lu, W., Zhou, Y., Hou, Y., Zhang, Y., Jiang, Y., Liu, H., \& Shao, Y. (2016). HDAC1 promoted migration and invasion binding with TCF12 by promoting EMT progress in gallbladder cancer. Oncotarget, 7(22). https://doi.org/10.18632/oncotarget.8740

Hetman, M., \& Slomnicki, L. P. (2019). Ribosomal biogenesis as an emerging target of neurodevelopmental pathologies. In Journal of Neurochemistry (Vol. 148, Issue 3, pp. 325-347). Blackwell Publishing Ltd. https://doi.org/10.1111/jnc.14576

Jones-Mason, M. E., Zhao, X., Kappes, D., Lasorella, A., lavarone, A., \& Zhuang, Y. (2012). E Protein Transcription Factors Are Required for the Development of CD4 + Lineage T Cells. Immunity, 36(3), 348-361. https://doi.org/10.1016/j.immuni.2012.02.010

Kang, S. H., Fukaya, M., Yang, J. K., Rothstein, J. D., \& Bergles, D. E. (2010). NG2+ CNS glial progenitors remain committed to the oligodendrocyte lineage in postnatal life and following neurodegeneration. Neuron, 68(4), 668-681. https://doi.org/10.1016/j.neuron.2010.09.009

Kessaris, N., Fogarty, M., lannarelli, P., Grist, M., Wegner, M., \& Richardson, W. D. (2006). Competing waves of oligodendrocytes in the forebrain and postnatal elimination of an embryonic lineage. Nature Neuroscience, 9(2), 173-179. https://doi.org/10.1038/nn1620

Labreche, K., Simeonova, I., Kamoun, A., Gleize, V., Chubb, D., Letouzé, E., Riazalhosseini, Y., Dobbins, S. E., Elarouci, N., Ducray, F., de Reyniès, A., Zelenika, D., Wardell, C. P., Frampton, M., Saulnier, O., Pastinen, T., Hallout, S., Figarella-Branger, D., Dehais, C., ... Wager, M. (2015). TCF12 is mutated in anaplastic oligodendroglioma. Nature Communications. https://doi.org/10.1038/ncomms8207

Lee, C.-C., Chen, W.-S., Chen, C.-C., Chen, L.-L., Lin, Y.-S., Fan, C.-S., \& Huang, T.-S. (2011). TCF12 Protein Functions as Transcriptional Repressor of E-cadherin, and Its Overexpression Is Correlated with Metastasis of Colorectal Cancer * $\square$ S. https://doi.org/10.1074/jbc.M111.258947

Lee, J. H., Lee, J. E., Kahng, J. Y., Kim, S. H., Park, J. S., Yoon, S. J., Um, J. Y., Kim, W. K., Lee, J. K., Park, J., Kim, E. H., Lee, J. H., Lee, J. H., Chung, W. S., Ju, Y. S., Park, S. H., Chang, J. H., Kang, S. G., \& Lee, J. H. (2018). Human glioblastoma arises from subventricular zone cells with low-level driver mutations. Nature, 560(7717), 243-247. https://doi.org/10.1038/s41586-018-0389-3

Li, Y., Brauer, P. M., Singh, J., Xhiku, S., Yoganathan, K., Zúñiga-Pflücker, J. C., \& Anderson, M. K. (2017). Targeted Disruption of TCF12 Reveals HEB as Essential in Human Mesodermal Specification and Hematopoiesis. Stem Cell Reports, 9(3), 779-795. https://doi.org/10.1016/j.stemcr.2017.07.011

Liberzon, A., Birger, C., Thorvaldsdóttir, H., Ghandi, M., Mesirov, J. P., \& Tamayo, P. (2015). The Molecular Signatures Database Hallmark Gene Set Collection. Cell Systems, 1(6). https://doi.org/10.1016/j.cels.2015.12.004

Liu, C., Sage, J. C., Miller, M. R., Verhaak, R. G. W., Hippenmeyer, S., Vogel, H., Foreman, O., Bronson, R. T., Nishiyama, A., Luo, L., \& Zong, H. (2011). Mosaic Analysis with Double Markers Reveals Tumor Cell of Origin in Glioma. Cell, 146(2), 209-221. https://doi.org/10.1016/J.CELL.2011.06.014

Liu, N., Song, J., Xie, Y., Wang, X.-L., Rong, B., Man, N., Zhang, M.-M., Zhang, Q., Gao, F.-F., Du, M.-R., Zhang, Y., Shen, J., Xu, C.-H., Hu, C.-L., Wu, J.-C., Liu, P., Zhang, Y.-L., Xie, Y.-Y., Liu, P., ... Sun, X.-J. (2019). Different roles of $E$ proteins in $t(8 ; 21)$ leukemia: E2-2 compromises the function of AETFC and negatively regulates leukemogenesis. Proceedings of the National Academy of Sciences, 116(3). https://doi.org/10.1073/pnas.1809327116

Louis, D. N., Perry, A., Reifenberger, G., von Deimling, A., Figarella-Branger, D., Cavenee, W. K., Ohgaki, H., Wiestler, O. D., Kleihues, P., \& Ellison, D. W. (2016). The 2016 World Health Organization Classification of Tumors of the Central Nervous System: a summary. Acta Neuropathologica, 131(6), 803-820. https://doi.org/10.1007/s00401-016-1545-1

Luo, C., Balsa, E., Perry, E. A., Liang, J., Tavares, C. D., Vazquez, F., Widlund, H. R., \& Puigserver, P. (2020). H3K27me3-mediated PGC1 $\alpha$ gene silencing promotes melanoma invasion through WNT5A and YAP. Journal of Clinical Investigation, 130(2). https://doi.org/10.1172/JCl130038

Marie, C., Clavairoly, A., Frah, M., Hmidan, H., Yan, J., Zhao, C., van Steenwinckel, J., Daveau, R., Zalc, B., Hassan, B., Thomas, J.-L., Gressens, P., Ravassard, P., Moszer, I., Martin, D. M., Lu, Q. R., \& Parras, C. (2018). Oligodendrocyte precursor survival and differentiation requires chromatin remodeling by $\mathrm{Chd7}$ and Chd8. Proceedings of the 


\section{National Academy of Sciences, 115(35), E8246-E8255.} https://doi.org/10.1073/pnas.1802620115

Marques, S., van Bruggen, D., Vanichkina, D. P., Floriddia, E. M., Munguba, H., Väremo, L., Giacomello, S., Falcão, A. M., Meijer, M., Björklund, Å. K., Hjerling-Leffler, J., Taft, R. J., \& Castelo-Branco, G. (2018). Transcriptional Convergence of Oligodendrocyte Lineage Progenitors during Development. Developmental Cell, 46(4), 504-517.e7. https://doi.org/10.1016/j.devcel.2018.07.005

Marques, S., Zeisel, A., Codeluppi, S., van Bruggen, D., Mendanha Falcao, A., Xiao, L., Li, H., Haring, M., Hochgerner, H., Romanov, R. A., Gyllborg, D., Munoz-Manchado, A. B., la Manno, G., Lonnerberg, P., Floriddia, E. M., Rezayee, F., Ernfors, P., Arenas, E., HjerlingLeffler, J., ... Castelo-Branco, G. (2016). Oligodendrocyte heterogeneity in the mouse juvenile and adult central nervous system. Science, 352(6291), 1326-1329. https://doi.org/10.1126/science.aaf6463

Massari, M. E., \& Murre, C. (2000). Helix-loop-helix proteins: regulators of transcription in eucaryotic organisms. Molecular and Cellular Biology, 20(2), 429-440. http://www.ncbi.nlm.nih.gov/pubmed/10611221

Mesman, S., \& Smidt, M. P. (2017). Tcf12 Is Involved in Early Cell-Fate Determination and Subset Specification of Midbrain Dopamine Neurons. Frontiers in Molecular Neuroscience, 10, 353. https://doi.org/10.3389/fnmol.2017.00353

Nakatani, H., Martin, E., Hassani, H., Clavairoly, A., Maire, C. L., Viadieu, A., Kerninon, C., Delmasure, A., Frah, M., Weber, M., Nakafuku, M., Zalc, B., Thomas, J. L., Guillemot, F., Nait-Oumesmar, B., \& Parras, C. (2013). Ascl1/Mash1 promotes brain oligodendrogenesis during myelination and remyelination. Journal of Neuroscience, 33(23), 9752-9768. https://doi.org/10.1523/JNEUROSCI.0805-13.2013

Neftel, C., Laffy, J., Filbin, M. G., Hara, T., Shore, M. E., Rahme, G. J., Richman, A. R., Silverbush, D., Shaw, M. L., Hebert, C. M., Dewitt, J., Gritsch, S., Perez, E. M., Gonzalez Castro, L. N., Lan, X., Druck, N., Rodman, C., Dionne, D., Kaplan, A., ... Suvà, M. L. (2019). An Integrative Model of Cellular States, Plasticity, and Genetics for Glioblastoma. Cell, 178(4), 835-849.e21. https://doi.org/10.1016/j.cell.2019.06.024

Noorani, I., de La Rosa, J., Choi, Y., Strong, A., Ponstingl, H., Vijayabaskar, M. S., Lee, J., Lee, E., Richard-Londt, A., Friedrich, M., Furlanetto, F., Fuente, R., Banerjee, R., Yang, F., Law, F., Watts, C., Rad, R., Vassiliou, G., Kim, J. K., ... Bradley, A. (2020). PiggyBac mutagenesis and exome sequencing identify genetic driver landscapes and potential therapeutic targets of EGFR-mutant gliomas. Genome Biology, 21(1). https://doi.org/10.1186/s13059-020-02092-2

Ostrom, Q. T., Gittleman, H., Liao, P., Vecchione-Koval, T., Wolinsky, Y., Kruchko, C., \& Barnholtz-Sloan, J. S. (2017). CBTRUS Statistical Report: Primary brain and other central nervous system tumors diagnosed in the United States in 2010-2014. Neuro-Oncology. https://doi.org/10.1093/neuonc/nox158

Parras, C., Marie, C., Zhao, C., \& Lu, Q. R. (2020). Chromatin remodelers in oligodendroglia. GLIA, 68(8), 1604-1618. https://doi.org/10.1002/glia.23837

Persson, A. I., Petritsch, C., Swartling, F. J., Itsara, M., Sim, F. J., Auvergne, R., Goldenberg, D. D., Vandenberg, S. R., Nguyen, K. N., Yakovenko, S., Ayers-Ringler, J., Nishiyama, A., Stallcup, W. B., Berger, M. S., Bergers, G., McKnight, T. R., Goldman, S. A., \& Weiss, W. A. (2010). Non-Stem Cell Origin for Oligodendroglioma. Cancer Cell, 18(6), 669-682. https://doi.org/10.1016/j.ccr.2010.10.033

Piazzi, M., Bavelloni, A., Gallo, A., Faenza, I., \& Blalock, W. L. (2019). Signal Transduction in Ribosome Biogenesis: A Recipe to Avoid Disaster. International Journal of Molecular Sciences, 20(11). https://doi.org/10.3390/ijms20112718

Rada-Iglesias, A., Bajpai, R., Swigut, T., Brugmann, S. A., Flynn, R. A., \& Wysocka, J. (2011). A unique chromatin signature uncovers early developmental enhancers in humans. Nature, 470(7333). https://doi.org/10.1038/nature09692

Ravanpay, A. C., \& Olson, J. M. (2008). E protein dosage influences brain development more than family member identity. Journal of Neuroscience Research. https://doi.org/10.1002/jnr.21615

Riemenschneider, M. J., Koy, T. H., \& Reifenberger, G. (2004). Expression of oligodendrocyte lineage genes in oligodendroglial and astrocytic gliomas. Acta Neuropathologica, 107(3), 277-282. https://doi.org/10.1007/s00401-003-0809-8 
Robinson, J. T., Thorvaldsdóttir, H., Winckler, W., Guttman, M., Lander, E. S., Getz, G., \& Mesirov, J. P. (2011). Integrative genomics viewer. Nature Biotechnology, 29(1). https://doi.org/10.1038/nbt.1754

Schindelin, J., Arganda-Carreras, I., Frise, E., Kaynig, V., Longair, M., Pietzsch, T., Preibisch, S., Rueden, C., Saalfeld, S., Schmid, B., Tinevez, J.-Y., White, D. J., Hartenstein, V., Eliceiri, K., Tomancak, P., \& Cardona, A. (2012). Fiji: an open-source platform for biological-image analysis. Nature Methods, 9(7). https://doi.org/10.1038/nmeth.2019

Sharma, V. P., Fenwick, A. L., Brockop, M. S., McGowan, S. J., Goos, J. A. C., Hoogeboom, A. J. M., Brady, A. F., Jeelani, N. O., Lynch, S. A., Mulliken, J. B., Murray, D. J., Phipps, J. M., Sweeney, E., Tomkins, S. E., Wilson, L. C., Bennett, S., Cornall, R. J., Broxholme, J., Kanapin, A., ... Wilkie, A. O. M. (2013). Mutations in TCF12, encoding a basic helixloop-helix partner of TWIST1, are a frequent cause of coronal craniosynostosis. Nature Genetics, 45(3), 304-307. https://doi.org/10.1038/ng.2531

Shen, Z., Lin, Y., Yang, J., Jörg, D. J., Peng, Y., Zhang, X., Xu, Y., Hernandez, L., Ma, J., Simons, B. D., \& Shi, S.-H. (2021). Distinct progenitor behavior underlying neocortical gliogenesis related to tumorigenesis. Cell Reports, 34(11). https://doi.org/10.1016/j.celrep.2021.108853

Slomnicki, L. P., Malinowska, A., Kistowski, M., Palusinski, A., Zheng, J.-J., Sepp, M., Timmusk, T., Dadlez, M., \& Hetman, M. (2016). Nucleolar Enrichment of Brain Proteins with Critical Roles in Human Neurodevelopment. Molecular \& Cellular Proteomics, 15(6). https://doi.org/10.1074/mcp.M115.051920

Sock, E., \& Wegner, M. (2019). Transcriptional control of myelination and remyelination. Glia, 67(11). https://doi.org/10.1002/glia.23636

Srinivas, S., Watanabe, T., Lin, C.-S., William, C. M., Tanabe, Y., Jessell, T. M., \& Costantini, F. (2001). Cre reporter strains produced by targeted insertion of EYFP and ECFP into the ROSA26 locus . BMC Developmental Biology, 1(1). https://doi.org/10.1186/1471-213X-14

Sugiarto, S., Persson, A. I., Munoz, E. G., Waldhuber, M., Lamagna, C., Andor, N., Hanecker, P., Ayers-Ringler, J., Phillips, J., Siu, J., Lim, D. A., Vandenberg, S., Stallcup, W., Berger, M. S., Bergers, G., Weiss, W. A., \& Petritsch, C. (2011). Asymmetry-defective oligodendrocyte progenitors are glioma precursors. Cancer Cell, 20(3), 328-340. https://doi.org/10.1016/j.ccr.2011.08.011

Sussman, C. R., Davies, J. E., \& Miller, R. H. (2002). Extracellular and intracellular regulation of oligodendrocyte development: Roles of Sonic hedgehog and expression of $E$ proteins. Glia, 40(1), 55-64. https://doi.org/10.1002/glia.10114

Suzuki, H., Aoki, K., Chiba, K., Sato, Y., Shiozawa, Y., Shiraishi, Y., Shimamura, T., Niida, A., Motomura, K., Ohka, F., Yamamoto, T., Tanahashi, K., Ranjit, M., Wakabayashi, T., Yoshizato, T., Kataoka, K., Yoshida, K., Nagata, Y., Sato-Otsubo, A., ... Ogawa, S. (2015). Mutational landscape and clonal architecture in grade II and III gliomas. Nature Genetics, 47(5), 458-468. https://doi.org/10.1038/ng.3273

Tirosh, I., Venteicher, A. S., Hebert, C., Escalante, L. E., Patel, A. P., Yizhak, K., Fisher, J. M., Rodman, C., Mount, C., Filbin, M. G., Neftel, C., Desai, N., Nyman, J., Izar, B., Luo, C. C., Francis, J. M., Patel, A. A., Onozato, M. L., Riggi, N., ... Suvà, M. L. (2016). Singlecell RNA-seq supports a developmental hierarchy in human oligodendroglioma. Nature. https://doi.org/10.1038/nature20123

Wedel, M., Fröb, F., Elsesser, O., Wittmann, M. T., Lie, D. C., Reis, A., \& Wegner, M. (2020). Transcription factor Tcf4 is the preferred heterodimerization partner for Olig2 in oligodendrocytes and required for differentiation. Nucleic Acids Research, 48(9), 48394857. https://doi.org/10.1093/nar/gkaa218

Weng, Q., Wang, J., Wang, J., He, D., Cheng, Z., Zhang, F., Verma, R., Xu, L., Dong, X., Liao, Y., He, X., Potter, A., Zhang, L., Zhao, C., Xin, M., Zhou, Q., Aronow, B. J., Blackshear, P. J., Rich, J. N., ... Lu, Q. R. (2019). Single-Cell Transcriptomics Uncovers Glial Progenitor Diversity and Cell Fate Determinants during Development and Gliomagenesis. Cell Stem Cell, 24(5), 707-723.e8. https://doi.org/10.1016/j.stem.2019.03.006

Wojciechowski, J., Lai, A., Kondo, M., \& Zhuang, Y. (2007). E2A and HEB are required to block thymocyte proliferation prior to pre-TCR expression. Journal of Immunology (Baltimore, Md. : 1950), 178(9), 5717-5726. http://www.ncbi.nlm.nih.gov/pubmed/17442955

Yi, S., Huang, X., Zhou, S., Zhou, Y., Anderson, M. K., Zúñiga-Pflücker, J. C., Luan, Q., \& Li, $Y$. (2020). E2A regulates neural ectoderm fate specification in human embryonic stem cells. Development. https://doi.org/10.1242/dev.190298 
Yi, S., Yu, M., Yang, S., Miron, R. J., \& Zhang, Y. (2017). Tcf12, A Member of Basic Helix-LoopHelix Transcription Factors, Mediates Bone Marrow Mesenchymal Stem Cell Osteogenic Differentiation In Vitro and In Vivo. Stem Cells. https://doi.org/10.1002/stem.2491

Yoon, S. J., Foley, J. W., \& Baker, J. C. (2015). HEB associates with PRC2 and SMAD2/3 to regulate developmental fates. Nature Communications, 6(1), 1-12. https://doi.org/10.1038/ncomms7546

Zhang, Y., Chen, K., Sloan, S. A., Bennett, M. L., Scholze, A. R., O'Keeffe, S., Phatnani, H. P., Guarnieri, P., Caneda, C., Ruderisch, N., Deng, S., Liddelow, S. A., Zhang, C., Daneman, R., Maniatis, T., Barres, B. A., \& Wu, J. Q. (2014). An RNA-sequencing transcriptome and splicing database of glia, neurons, and vascular cells of the cerebral cortex. Journal of Neuroscience, 34(36), 11929-11947. https://doi.org/10.1523/JNEUROSCI.1860-14.2014

Zhu, G., Yang, S., Wang, R., Lei, J., Ji, P., Wang, J., Tao, K., Yang, C., Ge, S., \& Wang, L. (2021). P53/mir-154 pathway regulates the epithelial-mesenchymal transition in glioblastoma multiforme cells by targeting tcf12. Neuropsychiatric Disease and Treatment, 17, 681-693. https://doi.org/10.2147/NDT.S273578

Zhuang, Y., Barndt, R. J., Pan, L., Kelley, R., \& Dai, M. (1998). Functional replacement of the mouse E2A gene with a human HEB cDNA. Molecular and Cellular Biology, 18(6), 33403349. https://doi.org/10.1128/mcb.18.6.3340

\section{Data Availability Statement}

ChIPseq and RNAseq data generated in this study are available through the Gene Expression Omnibus (data will be deposited upon acceptance of the manuscript). The data that support the findings of this study are available from the corresponding author upon reasonable request.

\section{Figure Legends}

Figure 1: TCF12 is altered in gliomas.

A. Bar graph showing the percentage of TCF12 altered samples in the glioblastoma (GBM, 592 samples) and lower grade glioma (LGG, 514 samples) cohorts from The Cancer Genome Atlas (TCGA). B. Pie charts illustrating the types of alterations in TCF12 altered gliomas of Figure 1A. C-D. Kaplan-Meier survival curves of TCGA LGGs ( $n=77$ altered, $n=418$ non altered, C) and GBMs ( $=95$ altered, $n=263$ non altered, D) comparing TCF12 altered vs non altered groups. E-F. Kaplan-Meier survival curves of TCGA LGGs ( $n=154$ high, n=359 low, E) and GBMs ( $n=46$ high, n=106 low, E) comparing high or low TCF12 mRNA expression.

\section{Supplementary Figure 1 (related to Figure 1)}

A. OncoPrint showing TCF12 alterations along with other genes commonly altered in gliomas (TCGA GBM/LGG cohort). Each column represents one sample. Only the TCF12 altered samples (210/1106) are displayed. The cumulative frequency of alterations of each gene observed in the total number of patient samples is indicated. B. Chart summarizing the estimated co-occurrence of TCF12 alterations with genes commonly altered in gliomas (from Supplementary Figure 1A). Statistical significance was determined with Fisher's exact test. Analysis was performed using the "Mutual Exclusivity" tool by "cbioportal". 
Figure 2: TCF12 is expressed in oligodendroglial cells

833 A. Bar graphs showing the expression of TCF12 mRNA in astrocytes, neurons and oligodendroglial cells in mouse (top) and human (bottom) brain (data extracted from https://www.brainrnaseq.org/) B. Reconstructed UMAP representation illustrating Tcf12 expression across oligodendroglia differentiation (direction of differentiation indicated by the arrow, yellow = low expression and dark blue $=$ high expression, related to Supplementary Figure 2 A-B). C. Dot plot showing mean Tcf12 expression and the percentage of Tcf12-expressing cells in each cluster shown in Supplementary Figure 2B. D. Schematic representation of the expression of selected OPC and OL markers (according to (Nakatani et al., 2013)). E-F. Immunostaining of TCF12 with PDGFRa (OPCs, E) or CC1 and OLIG1 (OLs, F) in the corpus callosum of postnatal (P15) and adult (P60) wild type mice. Scale bars, $20 \mu \mathrm{m}$. Insets represent $60 \%$ magnifications of the cells highlighted dash-lined squares. OPCs = oligodendrocyte precursor cells, OLs $=$ oligodendrocytes.

848 A. UMAP representing the compilation of the two single cell RNA-Seq data sets by Marques et al $2016 \& 2018$. B. UMAP with colored dots representing the 9 stages of differentiation (simplified clusters), from neural stem cells to mature myelinating oligodendrocytes. C. Dot plot summarizing the average mRNA expression of the three E proteins (Tcf12, Tcf3 and Tcf4) and the percentage of expressing cells in each one of the clusters of the Supplementary Figure 2B.

Figure 3: TCF12 mainly occupies active promoter regions in oligodendroglial cells

A. Venn diagrams illustrating the overlap of TCF12 bound sites and genes in NPCs and OPCs/OLs. B. Graphs depicting the annotation of TCF12 bound sites in NPCs (middle) and OPCs/OLs (right) with genomic regions compared to the region representation in the genome (left). C. Graphs showing the number of correlations of TCF12 peaks in NPCs (purple line) and OPCs/OLs (blue line) compared the central position of promoter (left) and enhancer (right) regions. D. Pie charts showing the distribution of TCF12 bound sites in promoter (left) and enhancer (right) regions in OPCs/OLs in association with epigenetic marks: H3K4me3 and H3K27Ac = active, $\mathrm{H} 3 \mathrm{~K} 4 \mathrm{me}=$ poised, $\mathrm{H} 3 \mathrm{~K} 27 \mathrm{me} 3=$ repressed, $\mathrm{NA}=$ no epigenetic mark. E. Representative ChIP-Seq tracks for TCF12, input control and active epigenetic marks (H3K4me3 and H3K27Ac) in Pdgfra, Itpr2, Mbp, Ki67 and Cdkn1a in promoter regions in OPCs/OLs. F. Bar plots showing significantly enriched terms and pathways in the TCF12 bound genes with active promoters in OPCs/OLs (6596 genes). For the

869 "MSigDB_Hallmark_2020" library, the top 15 most significant gene sets are displayed. 870 For the "GO_Biological_Process_2021" library, 15 among the top 50 most significant 871 gene sets are displayed.

874 A. Scheme illustrating the experimental strategy for the ChIP-Seq experiments. B. 875 Quantification of PDGFRa+ and CNP+ cells (as percentage of the total cells) of the 
immunofluorescence immunocytochemistry of cells that were plated directly after the MACSorting and kept in culture for 2 hours. PDGFRa+ cells are OPCs. CNP+ cells are mostly OLs (with some OPCs expressing CNP). Data are presented as mean + SEM. Individual points correspond to individual animals ( $n=6$ wild type mice). C. Pie charts showing the distribution of TCF12-bound sites between promoter (left) and enhancer (right) regions in NPCs and in association with epigenetic marks (H3K4me3 and $\mathrm{H} 3 \mathrm{~K} 27 \mathrm{Ac}=$ active, $\mathrm{H} 3 \mathrm{~K} 4 \mathrm{me}=$ poised, $\mathrm{H} 3 \mathrm{~K} 27 \mathrm{me} 3=$ repressed; $\mathrm{NA}=$ no epigenetic mark). E. Selected ChIP-Seq tracks for TCF12, input control and epigenetic marks in promoter regions of Mycn, Myc, Rp/5, Ruvb/2, Fb/ in OPCs/OLs.

\section{Figure 4: TCF12 inactivation in OPCs in vivo results in proliferation defects}

A. Schematic representation of the experimental procedure and timeline. B-C. Immunostaining of YFP (recognized by an anti-GFP antibody), with PDGFRa and Ki67 (B) or CC1 and OLIG1 (C) in the corpus callosum of tamoxifen induced Tcf1 $2^{\mathrm{ctrl}}$ and $T c f 12^{\text {hom }}$ pups at $\mathrm{P} 16$. Scale bars, $20 \mu \mathrm{m}$. In B, open arrowheads show recombined proliferating OPCs (PDGFRa+ Ki67+ GFP+) and white arrowheads show non proliferating recombined OPCs (PDGFRa+ Ki67- GFP+). In C, white arrows show recombined early OLs (CC1+ OLIG1- GFP+) and white arrowheads show recombined OPCs (CC1- OLIG1+ GFP+). D-I Quantification of the different populations within the recombined cells (GFP+) in P16 Tcf12 ctrr, $T c f 12^{\text {het }}$ and $T c f 12^{\text {hom }}$ tamoxifen induced pups. Individual points represent individual animals ( $\mathrm{n}=6 T c f 12^{\mathrm{ctt}}, \mathrm{n}=6 T c f 12^{\text {het }}$ and $\mathrm{n}=5$ $\left.T c f 12^{\text {hom }}\right)$. Data are presented as mean + SEM. Statistical differences were evaluated with one-way ANOVA and p-values (when differences are significant) are given on the graphs.

\section{Supplementary Figure 4 (related to Figure 4)}
A. Illustration of the genetics of the mouse lines used to create the Pdgfra-CreER ${ }^{T}$; Rosa26 $6^{\text {LSL-YFP }}$; TCf1 $2^{\text {flox }}$ mice. B. Genetics of the animals used for the experiments. C. Experimental procedure for the validation of the mouse model. D. RT-qPCR analysis of Tcf12 expression in O4+ MACSorted cells from P16 Tcf12 ctrr, Tcf12 het and Tcf12 $2^{\text {hom }}$ induced pups. Individual points correspond to individual animals ( $\mathrm{n}=3 T c f 12^{c t t r}, \mathrm{n}=3$ $T c f 12^{\text {het }}$ and $\mathrm{n}=4\left(T c f 2^{\text {hom }}\right)$. Data are presented as mean + SEM. Individual points represent individual animals. Statistical differences were evaluated with one-way ANOVA and p-values are given on the graphs. E. Quantification of GFP+, PDGFRa+ and OLIG2+ cells plated directly after the MACSorting and kept in culture for 2 hours. GFP+ cells are considered as recombined cells. PDGFRa+ cells are OPCs. OLIG2+ cells correspond to OPCs and OLs. Data are presented as mean + SEM. Individual points correspond to individual animals ( $\mathrm{n}=4 T c f 12^{\text {ctr }}, \mathrm{n}=3 T c f 12^{\text {het }}$ and $\left.\mathrm{n}=3 T c f 12^{\text {hom }}\right)$. Differences were analyzed with two-way (\% total cells) or one-way (\% recombined cells) ANOVA. No statistically significant differences were noted. F. Schematic representation of the experimental procedure and timeline for the P23 timepoint. G-H. Immunostaining of YFP (recognized by an anti-GFP antibody), with PDGFRa and Ki67 (B) or CC1 and OLIG1 (C) in the corpus callosum of tamoxifen induced Tcf12 $2^{\text {ctr }}$ and

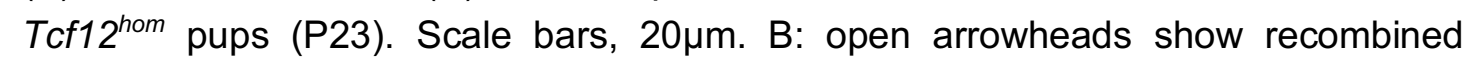


proliferating OPCs (PDGFRa+ Ki67+ GFP+) and white arrowheads show non proliferating recombined OPCs (PDGFRa+ Ki67- GFP+). C: white arrows show recombined OLs (CC1+ OLIG1+ GFP+) and white arrowheads show recombined OPCs (CC1- OLIG1+ GFP+). I-N. Quantification of the different populations within the recombined cells (GFP+) in P23 Tcf12 ctrr $T c f 12^{\text {het }}$ and $T c f 12^{\text {hom }}$ tamoxifen induced pups. Data are presented as mean + SEM. Individual points represent individual animals (animals quantified I-K: $n=5 T c f 12^{\text {ctlr }}, n=5 T c f 12^{\text {het }}$ and $n=4 T c f 12^{\text {hom }}$, animals quantified L-N: $\mathrm{n}=4 T c f 12^{c t r}, \mathrm{n}=4 T c f 12^{\text {het }}$ and $\left.\mathrm{n}=4 T c f 12^{\text {hom }}\right)$. Statistical differences were evaluated with one-way ANOVA. No statistically significant differences were noted.

\section{Figure 5: Transcriptomic analyses of Tcf12 inactivated cells highlight defects in OPC} proliferation, differentiation, and cancer-related pathways that are conserved in human gliomas.

A. Scheme illustrating the experimental strategy for the RNA-Seq experiments. B-C. Gene Set Enrichment Analysis (GSEA) of $T c f 12^{\text {hom }}$ vs $T c f 12^{\text {ctrl }}$ O4+ cells (OPCs/OLs) using curated oligodendroglial signatures (B) and MSigDB HALLMARKS gene sets (C). D. GSEA plots of selected gene sets of KEGG, HALLMARKS and REACTOME collections, comparing $T c f 12^{\text {hom }}$ vs Tcf1 $2^{\text {ctl }}$ animals. E. Gene Set Enrichment Analysis (GSEA) of oligodendrogliomas altered for TCF12 (TCF12ALTERED hODG, $\mathrm{n}=20$ ) compared to non-altered oligodendrogliomas (TCF12 ${ }^{\mathrm{WT}} \mathrm{hODG}, \mathrm{n}=35$ ) showing all significantly enriched gene sets of HALLMARK MSigDB collection. F. GSEA plots of selected gene sets for the REACTOME collection comparing TCF12 ALTERED vs TCF12 ${ }^{\mathrm{WT}}$ hODG.

\section{Supplementary Figure 5 (related to Figure 5)}

A-B. Gene Set Enrichment Analysis (GSEA) of Tcf12 ${ }^{\text {het }}$ vs Tcf12 $2^{\text {ctrl }}$ O4+ cells (OPCs/OLs) using curated oligodendroglial signatures $(A)$ and MSigDB HALLMARKS gene sets (B). C. Bar plots of GSEA normalized enrichment score (NES) of selected gene sets (positively and negatively enriched) from the GO_Biological_Process, KEGG and REACTOME collections of the MSigDB, comparing Tcf12 hom vs $T c f 12^{\text {ctrl }}$ animals. Adjusted p-values are given on the corresponding bars. 
bioRxiv preprint doi: https://doi.org/10.1101/2021.07.26.453859; this version posted July 27,2021 . The copyright holder for this preprint

1 (which was not certified by peer review) is the author/funder, who has granted bioRxiv a license to display the preprint in perpetuity. It is

A

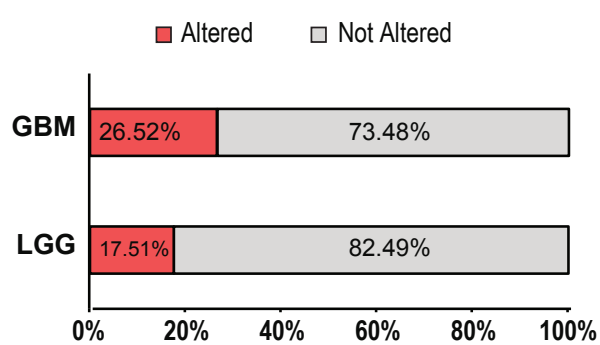

C

LGG TCF12 alteration status

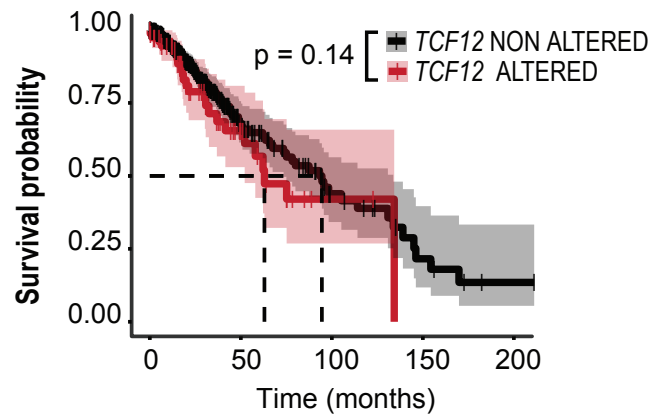

E

LGG TCF12 expression levels

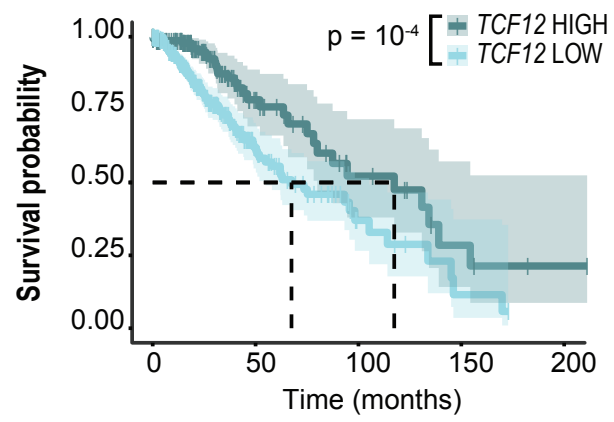

B TCF12 alteration types

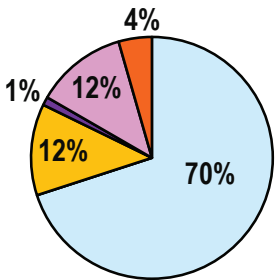

LGG

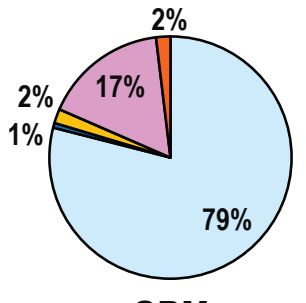

GBM
口TCF12 Heterozygous Loss

$\square T C F 12$ Homozygous Deletion

$\square T C F 12$ Gain

$\square T C F 12$ Mutation

$\square T C F 12$ Structural Variant

$\square T C F 12$ Multiple alterations

\section{GBM TCF12 alteration status}

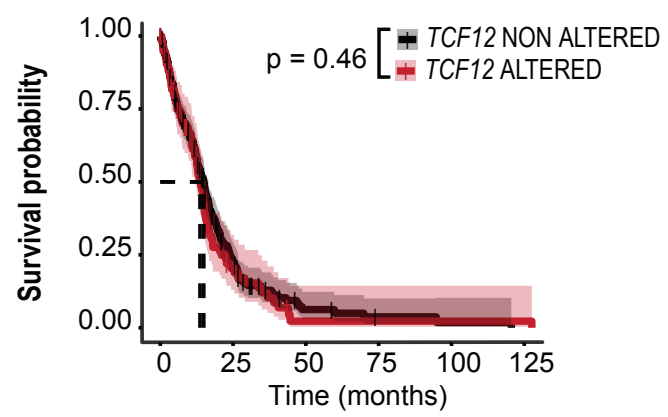

$F$

GBM TCF12 expression levels

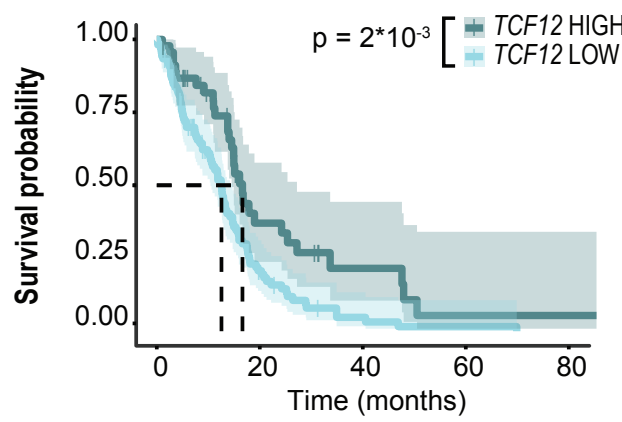


Figure 2(which was not certified by peer review) is the author/funder, who has granted bioRxiv a license to display the preprint in perpetuity. It is
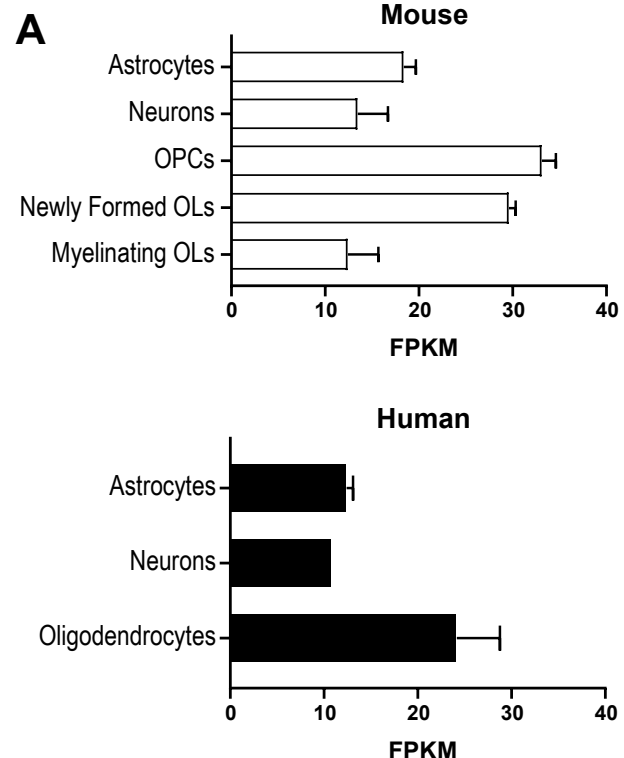
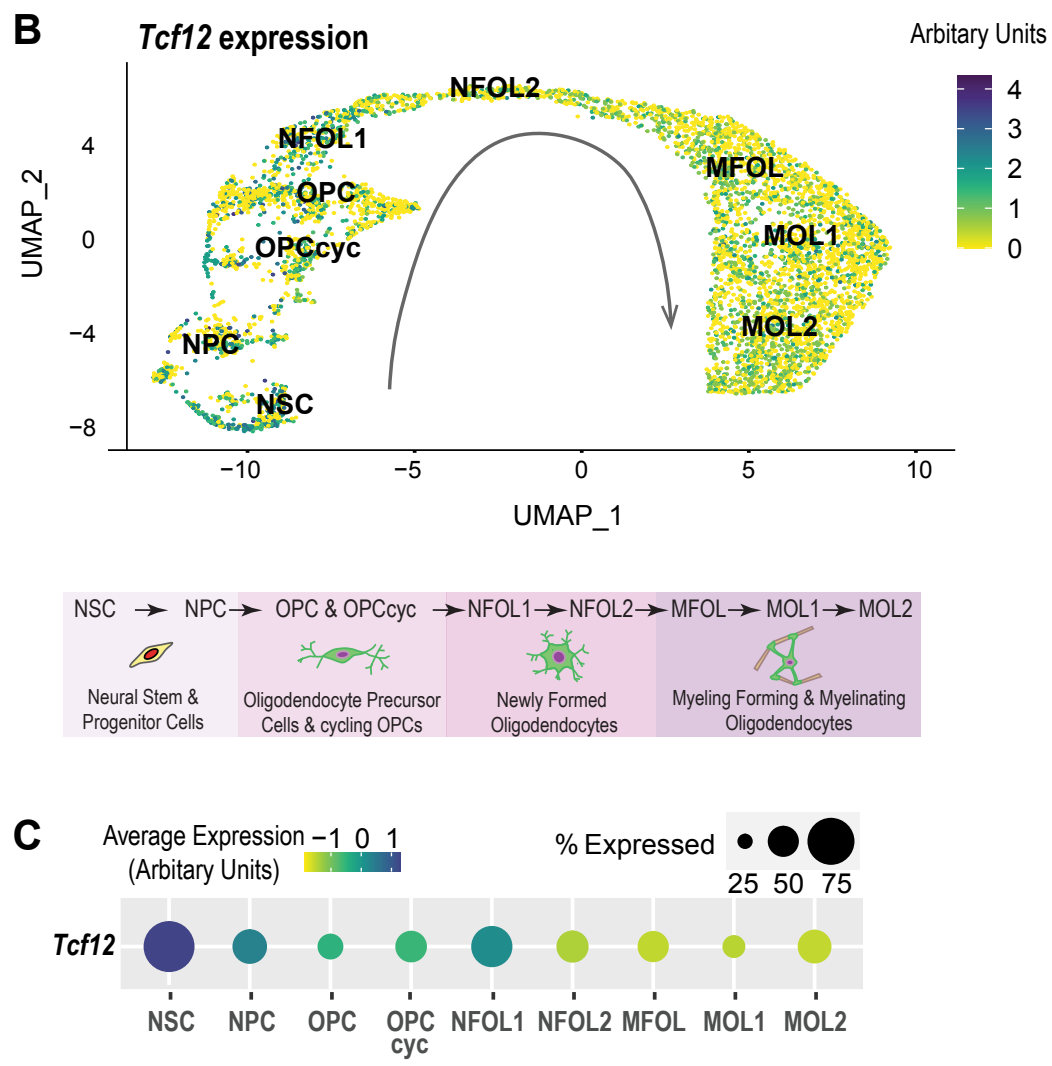

E

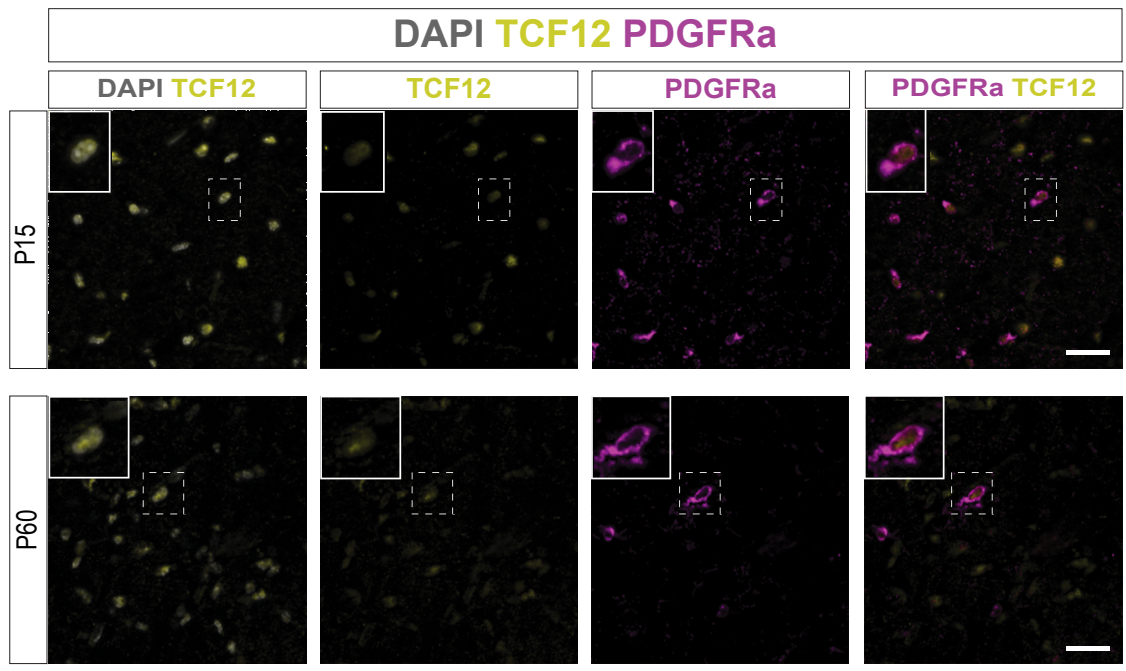

F
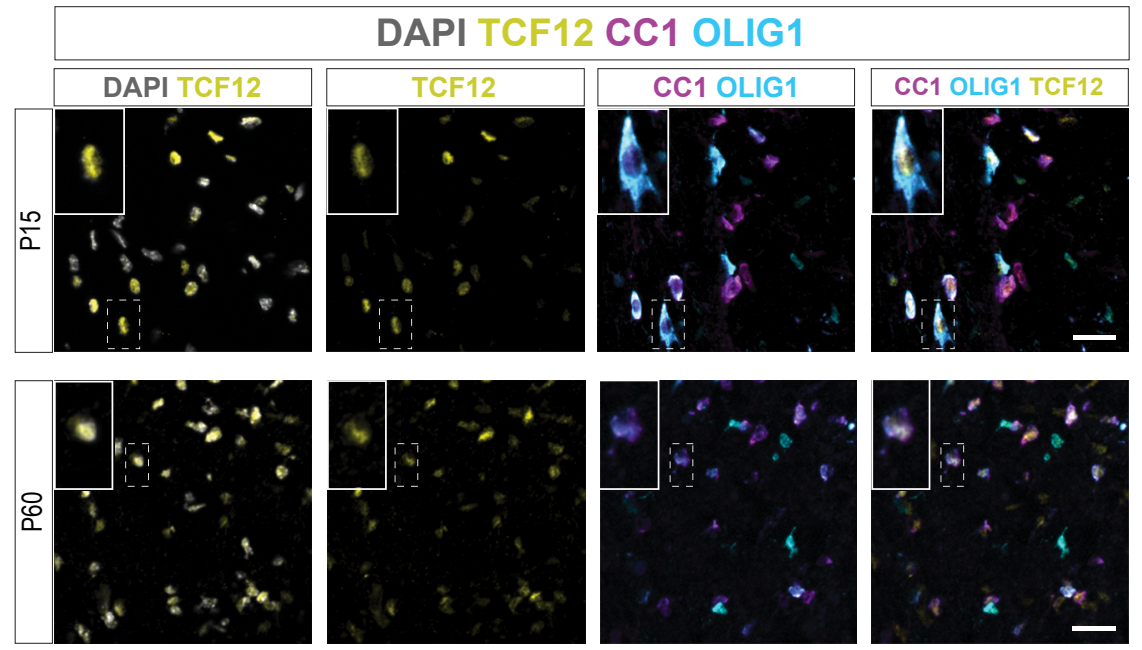
Figure 3 (which was not certified by peer review) is the author/funder, who has granted bioRxiv a license to display the preprint in perpetuity. It is made available under aCC-BY-NC-ND 4.0 International license.

A

TCF12 bound sites

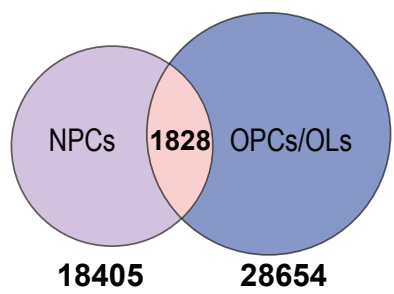

TCF12 bound genes

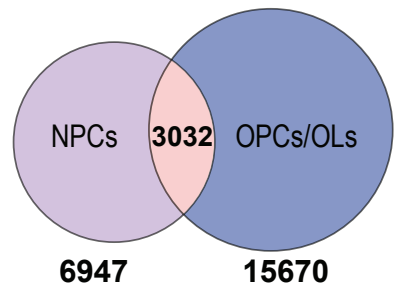

6947

B

口Promoter aExon alntron alntergenic

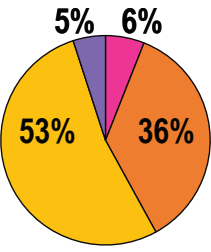

Mouse Genome Anotation
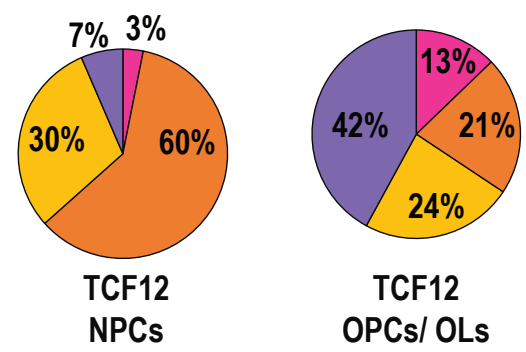

TCF12

OPCs/ OLs
C

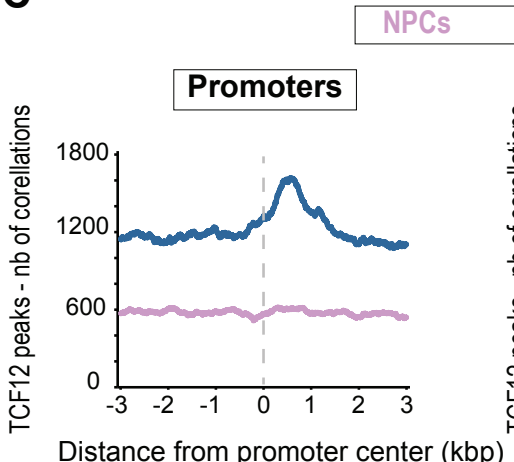

\section{OPCs/ OLs}

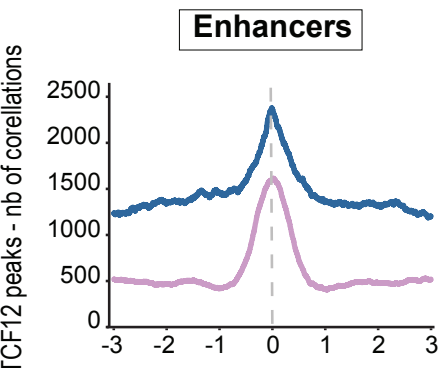

Distance from enhancer center (kbp)
D

\section{TCF12 - OPCs/OLs}

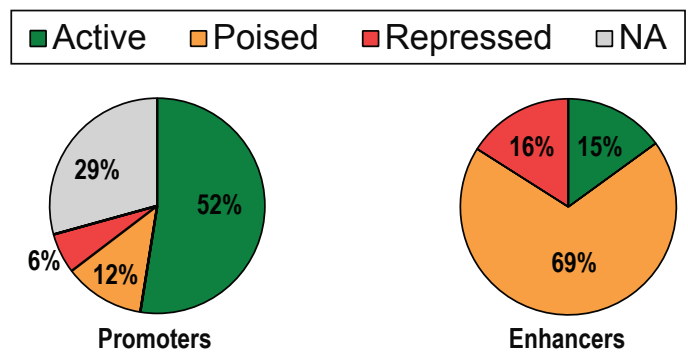

E

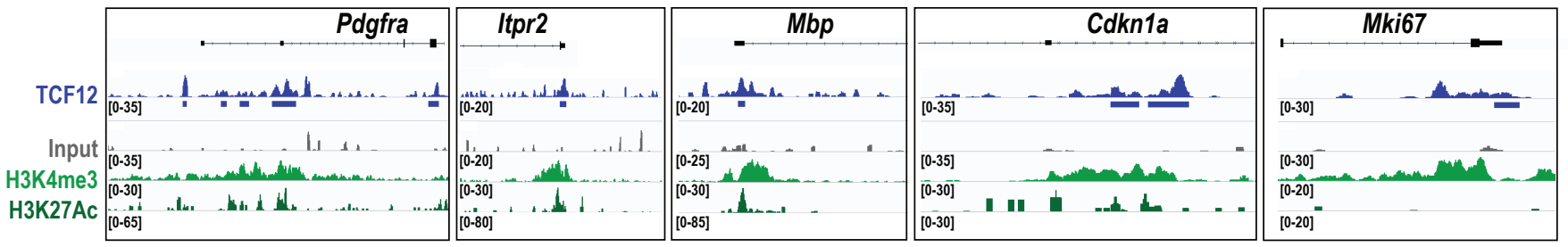

TCF12 - OPCs/OLs: Genes with active promoters

\section{MSigDB_Hallmark_2020}

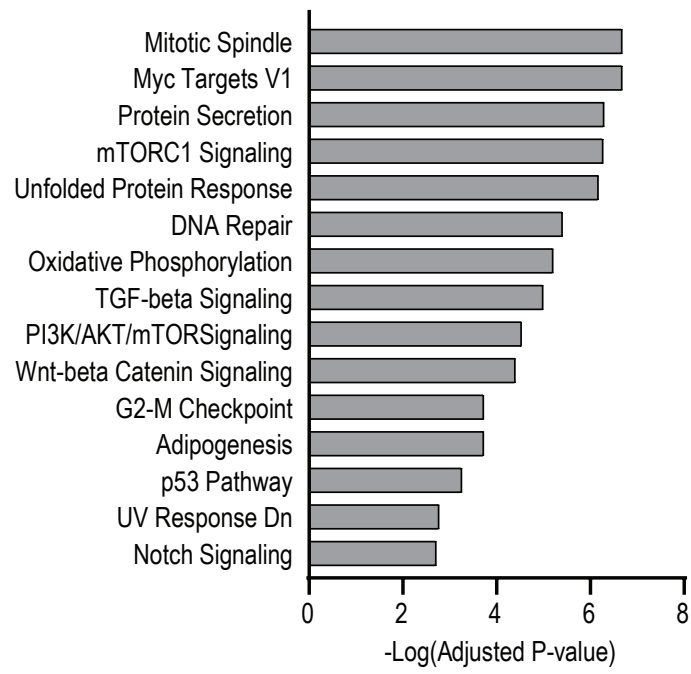

GO_Biological_Process_2021

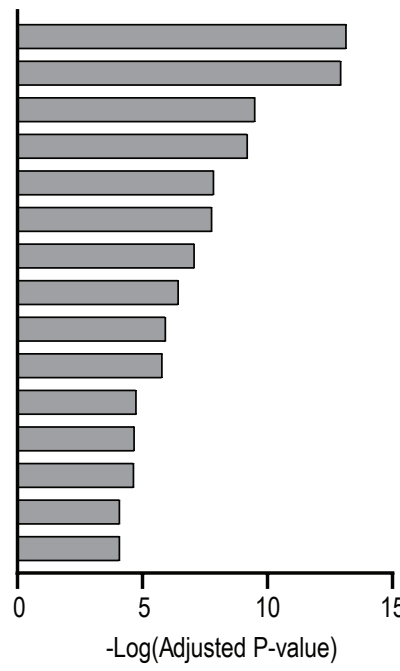

gene expression

ribosome biogenesis mRNA processing protein ubiquitination translation

cellular macromolecule biosynthetic process mRNA splicing, via spliceosome proteasomal protein catabolic process regulation of mitotic cell cycle regulation of signal transduction by $\mathrm{p} 53$ class mediator protein deubiquitination transcription, DNA-templated phosphorylation

post-translational protein modification RNA splicing 

made available under aCC-BY-NC-ND 4.0 International license.

A Pdgfra::CreERT $;$ Rosa26 $6^{\text {LSL-YFP }} ;$ Tcf12 ${ }^{\text {flox }}$

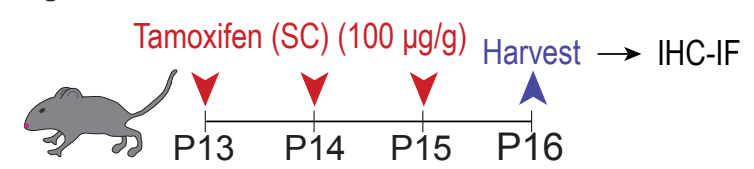

\section{B}

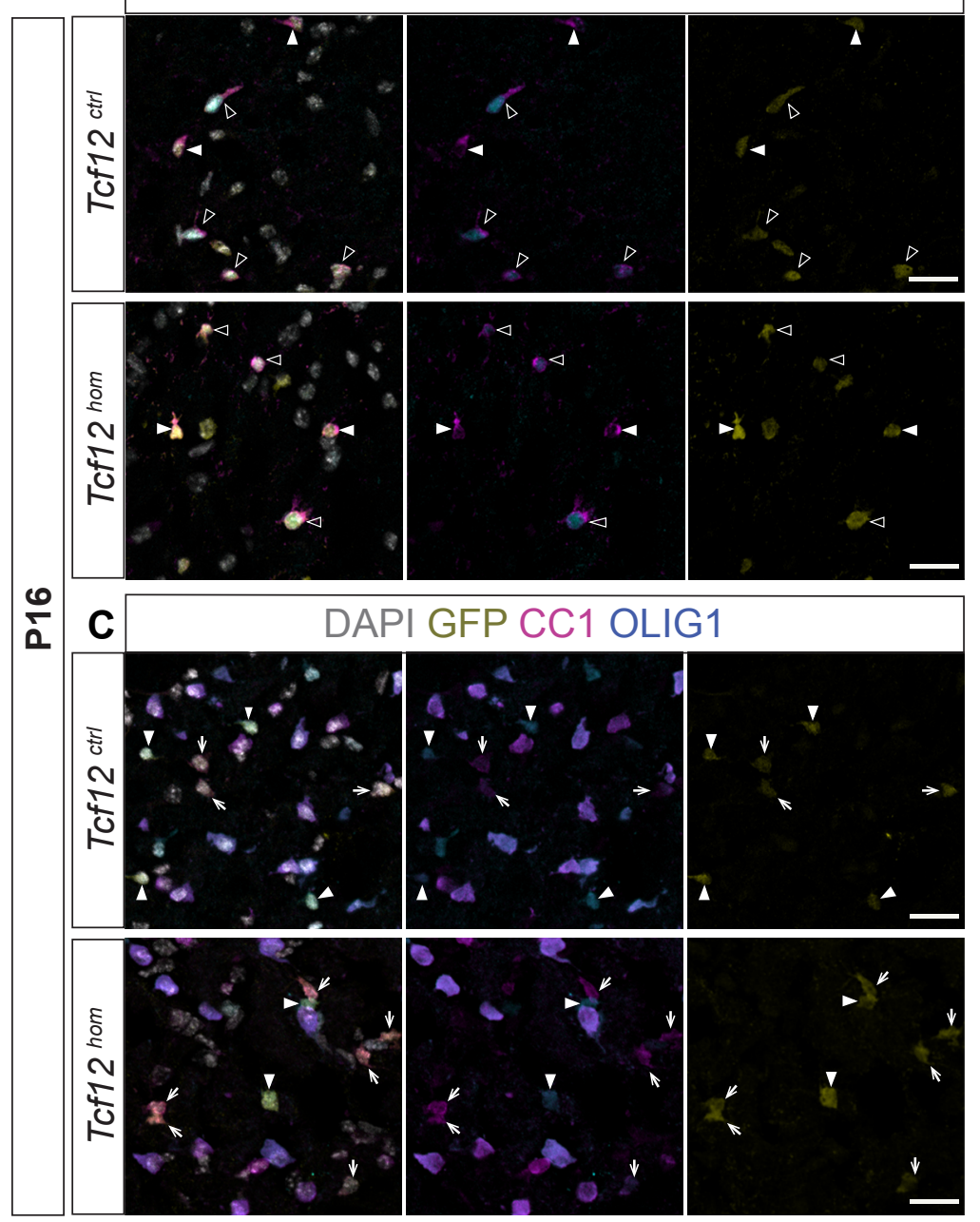

$\square$ Tcf12 ${ }^{\mathrm{ctrl}}$

Tcf12 het

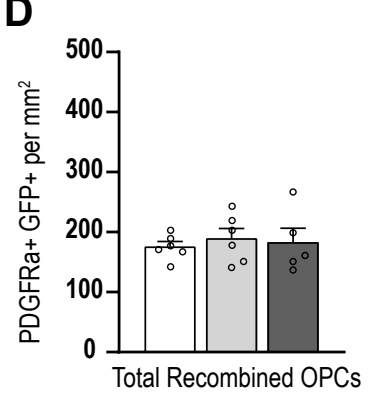

$\mathbf{F}$

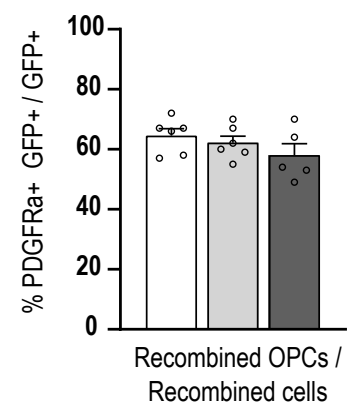

H

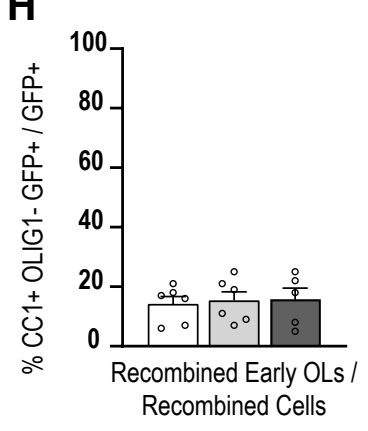

E

Tcf12 hom

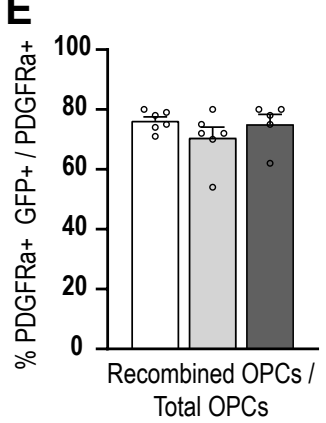

G
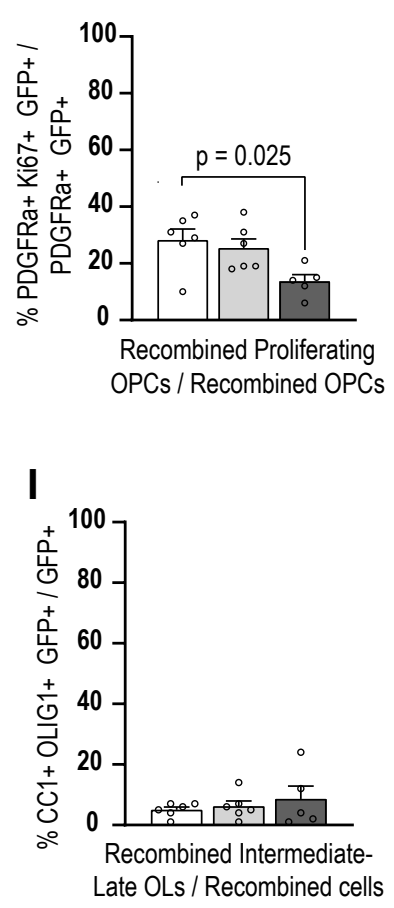
bigRxiv preprint doi: https://doi.org/10.1101/2021.07.26.453859; this version posted July 27, 2021. The copyright holder for this preprint Figurewaich was not certified by peer review) is the author/funder, who has granted bioRxiv a license to display the preprint in perpetuity. It is made available under aCC-BY-NC-ND 4.0 International license.

A

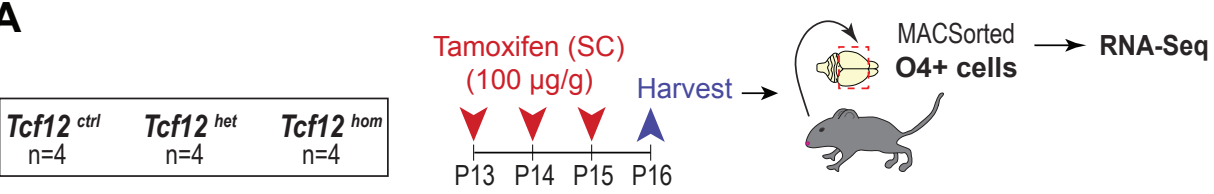

B
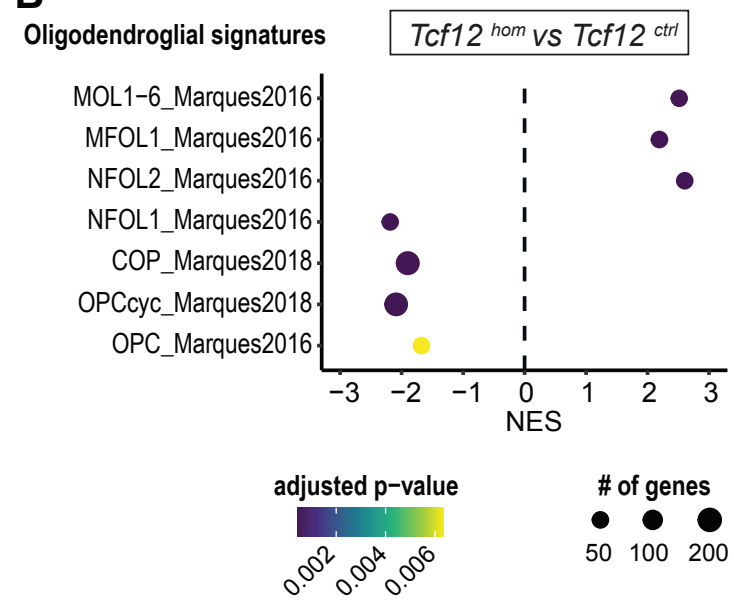

C

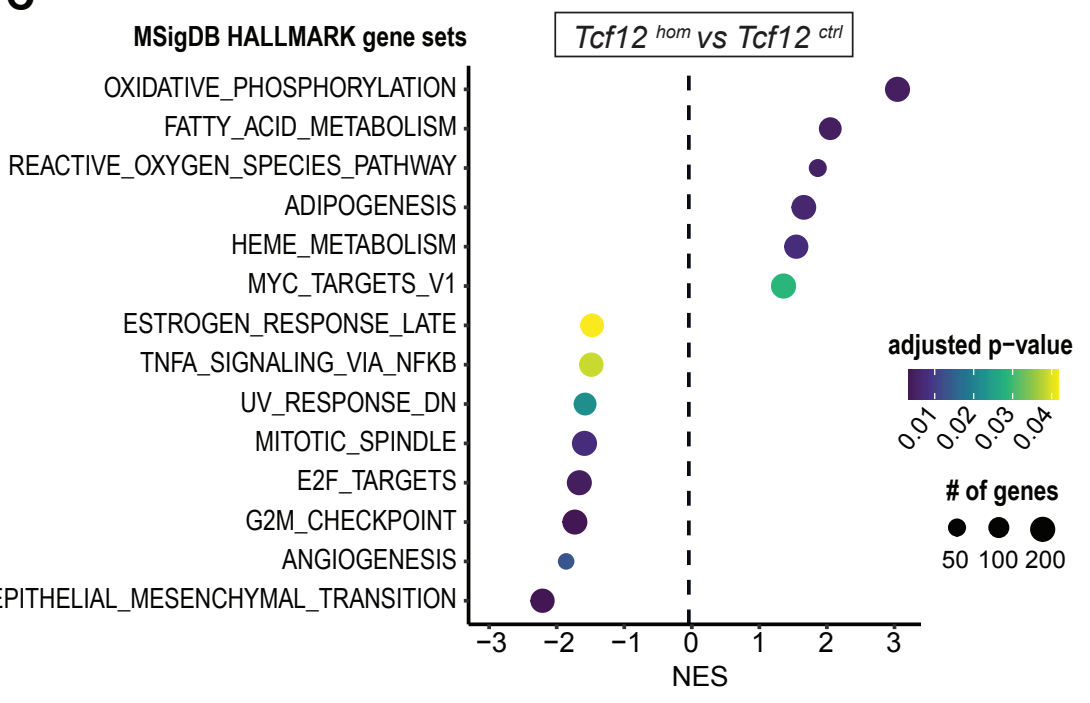

D Tcf1 $2^{\text {hom }}$ vs Tcf1 $2^{\mathrm{ctrl}}$

KEGG_RIBOSOME

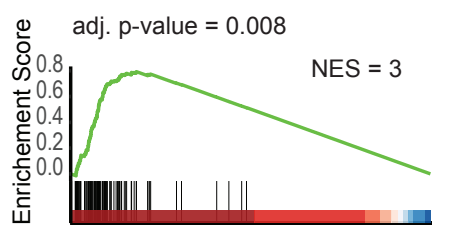

HALLMARK_MYC_TARGETS_V1

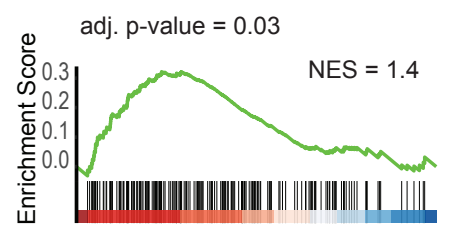

HALLMARK_OXIDATIVE_PHOSPHORYLATION

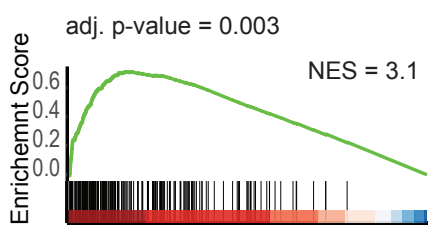

REACTOME_STABILIZATION_OF_P53

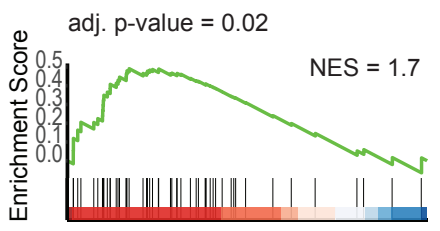

E

E

MSigDB HALLMARK gene sets

MYC_TARGETS_V
OXIDATIVE_PHOSPHORYLATION

MYC_TARGETS_V2

E2F_TARGETS

HEME_METABOLISM

EPITHELIAL_MESENCHYMAL_TRANSITION APOPTOSIS

ANDROGEN_RESPONSE

PROTEIN_SECRETION

BILE_ACID_METABOLISM

COMPLEMENT

COAGULATION

INTERFERON_ALPHA_RESPONSE INTERFERON_GAMMA_RESPONSE INFLAMMATORY_RESPONSE

\begin{tabular}{|c|c|}
\hline $\begin{array}{l}\text { TCF12 ALTERED } \\
n=20\end{array}$ & ${ }_{n=35}^{\text {TCF12 }}$ \\
\hline
\end{tabular}

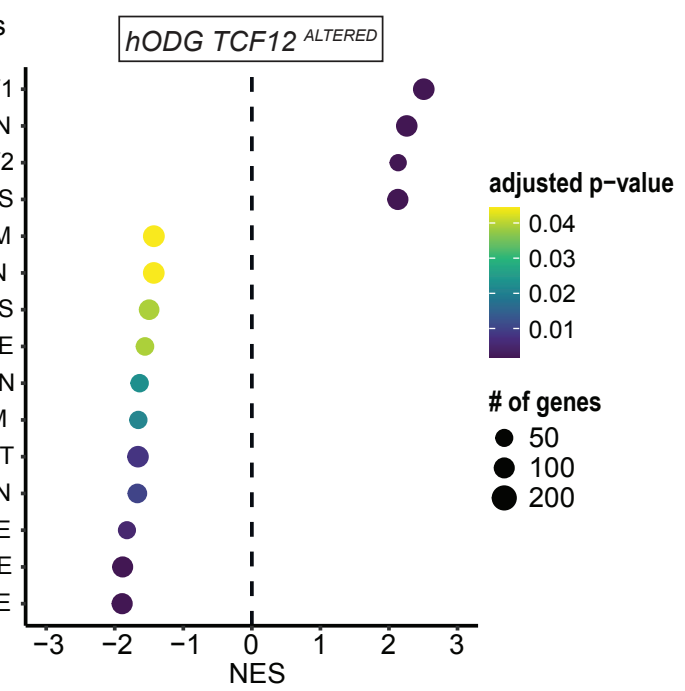

F hODG TCF12 $2^{\text {ALTERED }}$ vs hODG TCF12 ${ }^{\text {WT }}$ REACTOME_TRANSLATION

adjusted $p$-value $=0.005$

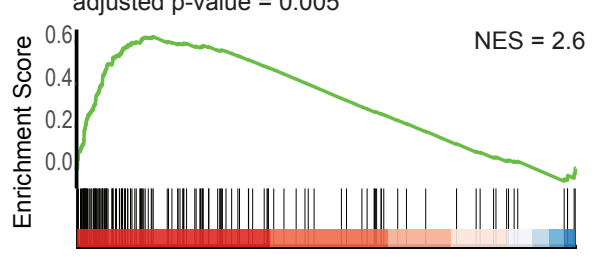

REACTOME_TRANSCRIPTIONAL_REGULATION_BY_TP53

adjusted $p$-value $=0.005$

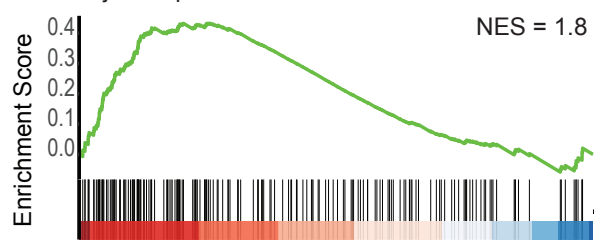

